Article

\title{
Macromolecular Dyes by Chromophore-Initiated Ring Opening Polymerization of L-Lactide
}

\author{
Francesca Cicogna ${ }^{1, *}$, Guido Giachi ${ }^{2}$, Luca Rosi ${ }^{2}{ }^{\circledR}$, Elisa Passaglia ${ }^{1}$, Serena Coiai ${ }^{1}{ }^{1}$, \\ Roberto Spiniello ${ }^{1}$, Federico Prescimone ${ }^{3,4}$ and Marco Frediani ${ }^{2}$ (I) \\ 1 Consiglio Nazionale delle Ricerche Istituto di Chimica dei Composti OrganoMetallici, \\ Sede Secondaria di Pisa (CNR ICCOM-SS-Pisa), 56124 Pisa, Italy; elisa.passaglia@pi.iccom.cnr.it (E.P.); \\ serena.coiai@pi.iccom.cnr.it (S.C.); roberto.spiniello@pi.iccom.cnr.it (R.S.) \\ 2 Dipartimento di Chimica "U. Schiff” Università degli Studi di Firenze, 50019 Sesto Fiorentino, Italy; \\ guidogiachi@gmail.com (G.G.); luca.rosi@unifi.it (L.R.); marco.frediani@unifi.it (M.F.) \\ 3 Dipartimento di Chimica e Chimica Industriale Università di Pisa, 56126 Pisa, Italy; \\ federico.prescimone@bo.ismn.cnr.it \\ 4 Consiglio Nazionale delle Ricerche Istituto per lo Studio dei Materiali Nanostrutturati Sede Secondaria \\ di Bologna, (CNR ISMN-SS-Bologna CNR), 40129 Bologna, Italy \\ * Correspondence: francesca.cicogna@pi.iccom.cnr.it; Tel.: +39-050-31523393
}

Received: 21 July 2020; Accepted: 28 August 2020; Published: 31 August 2020

\begin{abstract}
End functionalized polylactides are prepared by ring opening polymerization of L-lactide in the presence of stannous octoate $\left(\mathrm{Sn}(\mathrm{Oct})_{2}\right)$. Three chromophores, 9H-carbazol-ethanol (CA), 9-fluorenyl-methanol (FM), and 2-(4-(2-chloro-4-nitrophenylazo)-N-ethylphenylamino)ethanol (Disperse Red 13, DR), are for the first time used as co-initiators in the polymerization process. The polymerization reaction is initiated by conventional thermal treatment, but in the case of FM, microwave-assisted polymerization is also carried out. CA and FM absorb and emit in the UV portion of the electromagnetic spectrum, whereas DR absorbs in the visible part. The obtained end-capped polylactides derivatives show the same photophysical properties as the initiator, so they are "macromolecular dyes" (MDs) that can be used "as synthesized" or can be blended with commercial poly(lactic acid) (PLA). The blends of PLA with MDs have ultraviolet-visible (UV-Vis) absorption and fluorescence emission features similar to that of MDs and thermal properties typical of PLA. Finally, migration tests, carried out onto the blends of PLA with MDs and PLA with free chromophores, show that MDs are less released than free chromophores both in solution and in the solid phase.
\end{abstract}

Keywords: ring opening polymerization of L-lactide (RPO); chromophores end-capped PLA; dyed PLA; photophysical properties; migration tests; microwave-assisted polymerization

\section{Introduction}

Within the last decade, rising environmental concerns are contributing to increasing commercial interest over renewable and biodegradable polymers. In this context, poly(lactic acid) (PLA) is gaining more and more importance, and therefore, a widening of its properties is nowadays highly desirable. While a lot of research is focusing on improving its physicochemical and mechanical properties, fewer efforts are made to enhance and modify PLA optical features in the UV-Vis region. PLA features make it particularly useful for the production of fibers, packaging, and other applications; therefore, the final UV-barrier capabilities and aesthetic appearance of polymers are topic issues having strong influence on the performances of products [1]. PLA films absorb in the lower range of the electromagnetic spectrum but are almost transparent to radiations in the UV-A and UV-B regions ( $85 \%$ of light is transmitted 
at wavelength $(\lambda)$ about $250 \mathrm{~nm}$; $95 \%$ of light is transmitted at $\lambda>300 \mathrm{~nm}$ ). On the other hand, most widespread packaging polymers (cellophane, polystyrene (PS), and poly(ethylene-terephthalate) (PET)) have superior UV-barrier properties showing total absorptivity in the lower wavelength region. Moreover, with the development of large-scale production of PLA, its application in the production of fibers for textiles has gained increasing interest also because its dyeability is similar to that of other polyester materials [2,3]. Therefore, production of PLA having increased UV-Vis barrier properties can be used to design packaging tools suitable for protecting light-sensitive foods and goods or for product UV-shielding fibers for protecting fabrics. Simultaneously, the preparation of dyed PLAs can allow for production of aesthetically connoted plastic items or fibers for textiles or it can be used to produce sutures and implants that can be identified by the naked eye or by using a black light lamp. All these items represent remarkable achievements that can expand the potential applications of PLA. A possible strategy to obtain dyed or UV-protecting polymers is the addition of low molecular weight chromophores to the polymer matrix. However, generally, to extend the service life of polymers where additives are added, it is necessary to increase the affinity between additives and polymer matrices or to immobilize them by the formation of a covalent bond with the polymer backbone or by the use of host-guest systems. The formation of covalent bonds between the additive and polymer chains is probably the most interesting approach because it can prevent migration, volatilization, and possible loss by leaching of the additive. In the case of PLA, this can be carried out by synthesizing the polymer by ring opening polymerization (ROP) of lactide [4]. This is a well-documented polymerization methodology that ensures the production of functionalized end-capped PLA having high and controlled molecular weight. The polymerization process needs the use of a catalyst-generally stannous octoate but other catalysts are described [5-7]—and of a co-initiator-generally, an alcohol even though other systems are also reported in the literature [8]. Interestingly, the use of difunctional alcohols as co-initiators produces functionalized end-capped PLA. For example, by this route, PLAs bearing covalently bonded chromophores [9-11], UV absorbers [4,12], long alkyl chain [13-15], and fluoroalkyl chain [16] are described in the literature. In this paper, 9H-carbazol-ethanol (CA), 9-fluorenyl-methanol (FM), and 2-(4-(2-chloro-4-nitrophenylazo)-N-ethylphenylamino)ethanol (Disperse Red 13, DR) (Figure 1) are used for the first time as co-initiators for the synthesis of end-functionalized PLA.

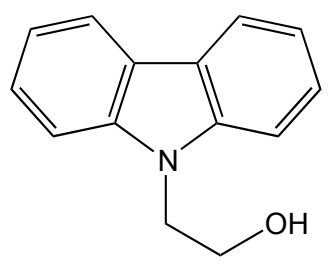

CA

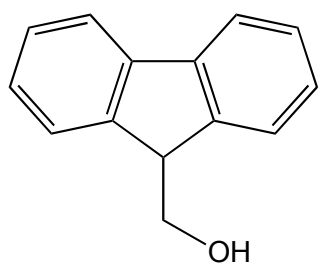

FM

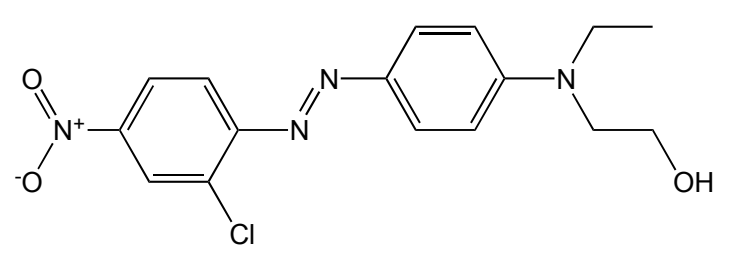

DR

(a)

(b)

(c)

Figure 1. (a) 9H-carbazol-ethanol (CA), (b) 9-fluorenyl-methanol (FM), and (c) 2-(4-(2-chloro-4 -nitrophenylazo)-N-ethylphenylamino)ethanol (Disperse Red 13, DR).

The three chromophores are selected on the basis of their UV-Vis characteristics with the aim to transfer their optical properties to the biodegradable polymer without changing its main features. FM and CA absorb in the UV-A and UV-B regions and emit by fluorescence in the range between 300 and $400 \mathrm{~nm}$, whereas DR is a commercially available dye with an absorption maximum at about $480 \mathrm{~nm}$ in chloroform (in the visible part of the electromagnetic spectrum). The end-functionalized polylactides produced by using CA, FM, or DR as initiators can be considered "macromolecular dyes" (MDs) that can be used "as synthesized" or can be blended with commercial PLA. By this way, dyed PLA can be obtained. The polymerization reaction of L-lactide is initiated by conventional thermal treatment that is carried out in the bulk, but in the case of FM, microwave-assisted polymerization was also used. To 
the best of our knowledge, chromophores in general and FM in particular have never been used before in the microwave-assisted polymerization of L-lactide. The details and results of this part are reported in a separate section at the end of the main text. All MDs are structurally characterized by size exclusion chromatography (SEC), Fourier transform infrared (FT-IR) spectroscopy, and proton nuclear magnetic resonance $\left({ }^{1} \mathrm{H}-\mathrm{NMR}\right)$ analysis. Thermal properties are evaluated by differential scanning calorimetry (DSC) analysis, and photo-physical features are determined by ultraviolet (UV)-visible absorption (UV-Vis) spectroscopy and fluorescence emission spectroscopy. Finally, migration tests on samples where MDs are mixed with PLA are carried out under different experimental conditions and the results are compared with those obtained for samples obtained by mixing the free chromophores with PLA.

\section{Materials and Methods}

\subsection{Materials and Reagents}

PLA 2002D containing 96\% of L-lactide and supplied by NatureWorks ${ }^{\circledR}$, Minnetonka, Minnesota USA having melt flow index (MFI) $(2.16 \mathrm{~kg} / 190 \mathrm{C}) 4-8 \mathrm{~g} / 10 \mathrm{~min}$, was used as a polymer matrix. Before processing, PLA was dried in a vacuum oven at $110^{\circ} \mathrm{C}$ for $12 \mathrm{~h}$. 9H-carbazole-ethanol (CA, Aldrich, St. Louis, Missouri, USA), 9-fluorenyl-methanol (FM, Aldrich; St. Louis, Missouri, USA), 2-[4-(2-chloro-4-nitrophenylazo)-N-ethyl-phenylamino]ethanol (disperse red 13, DR, Aldrich), tin(II) 2-ethylhexanoate or stannous octoate (Sn(Oct) $)_{2}$ (Aldrich, St. Louis, Missouri, USA), chloroform (for HPLC, $\geq 99.8 \%$, contains $0.5-1.0 \%$ of ethanol as stabilizer) were used as received. L-lactide (Aldrich, St. Louis, Missouri, USA) was sublimed before use.

\subsection{Conventional Synthesis of Macromolecular Dyes (MDs)}

Sublimed L-lactide (approx. $2 \mathrm{~g}$ ) was heated in bulk, under nitrogen atmosphere, in a Schlenk tube at $130{ }^{\circ} \mathrm{C}$ for $3 \mathrm{~h}$ in the presence of $\mathrm{Sn}(\mathrm{Oct})_{2}(0.5 \mathrm{~mol} \%$ with respect to L-lactide) and CA, FM, or DR (1, $3,5,7$, or $10 \mathrm{~mol} \%$ with respect to L-lactide) to obtain macromolecular dyes. The new products were named MD followed by the acronym of co-initiator and a number corresponding to the percentage of co-initiators used in the synthesis. For example, MD end capped with CA prepared by using $5 \mathrm{~mol} \%$ of co-initiator was named MDCA5. Analogously, MD end-capped with FM prepared by using $5 \mathrm{~mol} \%$ of co-initiator was named MDFM5, and MD end-capped with DR prepared by using $5 \mathrm{~mol} \%$ of co-initiator was named MDDR5. Purified polymers were obtained by dissolving the crude product in chloroform $(20 \mathrm{~mL})$, followed by precipitation that was carried out by slow and controlled addition of $\mathrm{n}$-hexane. The precipitate was recovered by filtration with a Büchner funnel (for powdery, higher-molecular weight polylactides) or decantation (viscous liquid, lower-molecular weight polylactides). Products were isolated in good to excellent yields (75\%-95\%) after drying overnight in a vacuum (approx. 50 Torr) at room temperature. The conversion of L-lactide was evaluated by considering the ratio between its unreacted amount at the end of reaction and its amount in the feed. The amount of unreacted lactide was quantitatively evaluated by ${ }^{1} \mathrm{H}-\mathrm{NMR}$ by the signal integration of the quartet associated with the $\mathrm{C} \underline{\mathrm{H}}$ of residual L-lactide (5.04 ppm) and that of the repetitive unit of MDs (5.16 ppm) (Figure S1 Supplementary Materials). To evaluate the absence of residual free chromophores, ${ }^{1} \mathrm{H}-\mathrm{NMR}$ analysis of crude products was used. A shift of the methylene protons in the alpha position of hydroxyl group upon formation of the ester bond between the hydroxyl group and PLA chain was observed. The polymerization degree (PD) (the number of lactic acid repeating units in the polymer) was evaluated by calculating the ratio between the integral of the quartet associated with $\underline{\mathrm{H}}$ of repeating unit of $\mathrm{MD}(5.16 \mathrm{ppm})$ and that of the terminal lactic acid unit $(4.36 \mathrm{ppm})$. The conversion of L-lactide to MDs, PD, number average molecular weight (Mn) determined by ${ }^{1} \mathrm{~N}-\mathrm{NMR}$ and by SEC, Mn calculated on the basis of the L-lactide/co-initiator ratio in the feed and dispersity (Đ) calculated as weight average molecular weight $(\mathrm{Mw})$ and $\mathrm{Mn}$ ratio $(\mathrm{Mw} / \mathrm{Mn})$ evaluated by SEC are reported in Table 1. 
Table 1. Conversion of L-lactide to Macromolecular Dyes (MDs), polymerization degree (PD), number average molecular weight $(\mathrm{Mn})$ determined by proton nuclear magnetic resonance ${ }^{1} \mathrm{H}-\mathrm{NMR}$ and by size exclusion chromatography (SEC), Mn calculated on the basis of L-lactide/initiator in the feed, and dispersity $(\bigoplus=\mathrm{Mw} / \mathrm{Mn})$ determined by SEC.

\begin{tabular}{|c|c|c|c|c|c|c|}
\hline Entry & $\begin{array}{c}\text { Conversion } \\
(\%)^{1}\end{array}$ & $\begin{array}{c}\text { PD } \\
\left(_{(N M R)^{2}}\right.\end{array}$ & $\begin{array}{c}\text { Mn (NMR) } \\
(\mathrm{g} / \mathrm{mol})^{3}\end{array}$ & $\begin{array}{l}\operatorname{Mn}(\mathrm{SEC}) \\
(\mathrm{g} / \mathrm{mol})^{4}\end{array}$ & $\begin{array}{l}\text { Mn (CAL) } \\
(\mathrm{g} / \mathrm{mol})^{5}\end{array}$ & $Đ(\mathrm{SEC})^{6}$ \\
\hline MDCA1 & 93 & 41 & 3166 & 12,702 & 13,616 & 1.5 \\
\hline MDCA3 & 99 & 26 & 2085 & 5452 & 7346 & 1.4 \\
\hline MDCA5 & 99 & 28 & 2229 & 4002 & 3065 & 1.3 \\
\hline MDCA7 & 91 & 17 & 1436 & 2633 & 2085 & 1.4 \\
\hline MDCA10 & 88 & 13 & 1148 & 2088 & 1480 & 1.3 \\
\hline MDFM1 & 92 & 9 & 845 & 2262 & 13,457 & 1.2 \\
\hline MDFM3 & 91 & 10 & 917 & 2146 & 4568 & 1.1 \\
\hline MDFM5 & 99 & 26 & 2142 & 3822 & 3050 & 1.2 \\
\hline MDFM7 & 99 & 19 & 1566 & 1682 & 2234 & 1.1 \\
\hline MDFM10 & 99 & 4 & 485 & 1334 & 1623 & 1.1 \\
\hline MDDR1 & 84 & 6 & 781 & 2320 & 12,456 & 1.2 \\
\hline MDDR3 & 85 & 10 & 1069 & 2407 & 4432 & 1.1 \\
\hline MDDR5 & 82 & 28 & 2367 & 2204 & 2713 & 1.1 \\
\hline MDDR7 & 82 & 7 & 853 & 1218 & 2037 & 1.1 \\
\hline MDDR10 & 82 & 4 & 637 & 754 & 1531 & 1.1 \\
\hline
\end{tabular}

${ }^{1}$ Conversion of lactide $\left(\left(\mathrm{LA}_{0}-\mathrm{LA}\right) / \mathrm{LA}_{0}\right) \times 100$, where $\mathrm{LA}_{0}$ is the amount of L-lactide in the feed and LA is the amount of unreacted L-lactide at the end of reaction. The amount of unreacted L-lactide is quantitatively evaluated by ${ }^{1} \mathrm{H}-\mathrm{NMR}$ by the signal integration of the quartet associated with the $\mathrm{C} \underline{\mathrm{H}}$ of residual L-lactide (5.04 $\mathrm{ppm}$ ) and that of the repetitive unit of MDs (5.16 ppm). ${ }^{2}$ Determined by calculating the ratio between integrals of $\mathrm{CH}$ quartet in the repetitive unit $(5.16 \mathrm{ppm})$ and terminal $\underline{\mathrm{CH}}$ quartet $(4.36 \mathrm{ppm})$ of MDs; values are approximated to the nearest whole number. ${ }^{3} \mathrm{Mn}$ determined by ${ }^{1} \mathrm{H}-\mathrm{NMR}$ analysis $\left(\mathrm{PD} \times 72\right.$ (lactic acid molecular weight) $+\mathrm{M}_{\mathrm{i}}$, where $\mathrm{M}_{\mathrm{i}}$ is the molecular weight of the initiator. ${ }^{4} \mathrm{Mn}$ determined by SEC analysis and corrected by multiplying 0.58 [12]. ${ }^{5}$ Theoretically calculated $\mathrm{Mn}=144.137$ (molecular weight of lactide) $\times\left(\mathrm{LA}_{0} / \mathrm{I}_{0}\right) \times$ conversion $+\mathrm{M}_{\mathrm{i}}$, where $\mathrm{I}_{0}$ is the mole of co-initiator in the feed. ${ }^{6}$ Dispersity $(\mathrm{D}=\mathrm{Mw} / \mathrm{Mn})$ determined by SEC analysis.

\subsection{Blending of Commercial PLA with MD (PLA/MD5s)}

PLA and MD blends were prepared by using a discontinuous mechanical mixer Brabender Plastograph OHG47055 with a chamber of $30 \mathrm{cc}$. Torque and temperature data were acquired by the Brabender Mixing software WinMix ver. 1.0. Blending was carried out at $180^{\circ} \mathrm{C}$ by mixing $20 \mathrm{~g}$ of PLA with $200 \mathrm{mg}$ of MD containing about $5 \mathrm{~mol} \%$ of chromophore (MDFM5, MDCA5, and MDDR5) at $50 \mathrm{rpm}$ for $10 \mathrm{~min}$. The prepared samples were PLA/MDFM5, PLA/MDCA5, and PLA/MDFM5.

\subsection{Blending of Commercial PLA with Chromophores (PLA/CHROs)}

Analogous to the preparation of PLA/MDs, $20 \mathrm{~g}$ of PLA was blended with about $10 \mathrm{mg}$ of CA, FM, or DR (the correct amount was evaluated on the basis of the data reported in Table S1, Supplementary Materials) at $180^{\circ} \mathrm{C}$ by using a discontinuous mechanical mixer. The prepared samples were PLA/FM, PLA/CA, and PLA/DR.

\subsection{Migration Test}

Tests for solvent extraction resistance were carried out by cutting about $100 \mathrm{mg}$ of films of PLA/CHRO or PLA/MD into pieces of $2 \mathrm{~mm} \times 2 \mathrm{~mm}$ that were suspended in $3 \mathrm{~mL}$ of EtOH $95 \%\left(\mathrm{EtOH} / \mathrm{H}_{2} \mathrm{O} 95 / 5 \mathrm{v} / \mathrm{v}\right)$ at $40{ }^{\circ} \mathrm{C}$ for $90 \mathrm{~min}$. Solutions were analyzed by UV-Vis absorption spectroscopy. The percentage of extracted chromophores was calculated on the basis of the total amount of chromophore in the tested specimen.

In the case of PLA/DR and PLA/MDDR5, other migration tests were carried out to check the transfer of the red color from the pristine PLA sample to another polymer film. Accordingly, films of PLA/DR or PLA/MDDR5 were put in contact with PET or styrene butadiene copolymer (SBC) films. To speed 
up transfer of the color, PLA samples and PET films were hot compressed at $130{ }^{\circ} \mathrm{C}$ (lower than the melting temperature of PLA samples and of PET) for $30 \mathrm{~min}$ at 1.2 tons. The experiments were repeated at $100^{\circ} \mathrm{C}$ or $120^{\circ} \mathrm{C}$ for $30 \mathrm{~min}$ by using SBC film in place of PET. Other tests were carried out to check the migration of dyes inside the polymer matrix in the melt. Accordingly, film of PLA/CA or PLA/MDCA5 were hot melted at $180^{\circ} \mathrm{C}$ in a parallel plate heating press between aluminum and Teflon sheets for $5 \mathrm{~min}$ at 1 ton. The hot samples were quenched at $-18{ }^{\circ} \mathrm{C}$ for $15 \mathrm{~min}$ and then analyzed. The same samples were placed again between aluminum and Teflon sheets and were annealed at $110^{\circ} \mathrm{C}$ for $16 \mathrm{~h}$ in an oven. The film surfaces were characterized by fluorescence emission spectroscopy.

\subsection{Instruments}

Size exclusion chromatography (SEC) analysis was carried out by the Agilent Technologies 1200 Series instrument equipped with an Agilent degasser, an isocratic high performance liquid chromatography (HPLC) pump, an Agilent refractive index (RI) detector, one pre-column PLgel 5 $\mu \mathrm{m}$ guard, and two PLgel MiniMIX-D $5 \mu \mathrm{m}$ columns conditioned at $35^{\circ} \mathrm{C}$. Chloroform $\left(\mathrm{CHCl}_{3}\right)$ was used as mobile phase at a flow rate of $0.3 \mathrm{~mL} / \mathrm{min}$. The system was calibrated with polystyrene standards in a range from 500 to $3 \times 10^{5} \mathrm{~g} / \mathrm{mol}$. Samples were dissolved in $\mathrm{CHCl}_{3}(2 \mathrm{mg} / \mathrm{mL})$ and filtered through a $0.20-\mu \mathrm{m}$ syringe filter before analysis. Mn and $\mathrm{Mw}$ were determined using Agilent ChemStation software.

FT-IR spectra were collected by Fourier Transform Spectrometer Perkin Elmer Spectrum 100.

${ }^{1} \mathrm{H}-\mathrm{NMR}$ spectra were recorded in $\mathrm{CDCl}_{3}$ solutions by means of a Varian VXR 200 spectrometer operating at $200 \mathrm{MHz}$ for $1 \mathrm{H}$.

Differential scanning calorimetry (DSC) experiments were performed using a Perkin Elmer DSC 7 calorimeter equipped with a liquid nitrogen low-temperature apparatus. Previously, the instrument was calibrated by using lead (m.p. $327.46^{\circ} \mathrm{C}$ ) and indium (m.p. $156.6^{\circ} \mathrm{C}, \Delta H_{\mathrm{m}}=28.5 \mathrm{~J} / \mathrm{g}$ ) as references. Thermal scans were carried out on 5-10 mg samples under nitrogen atmosphere using aluminum pans. Samples were analyzed from $40{ }^{\circ} \mathrm{C}$ to $220^{\circ} \mathrm{C}$ (1st heating) at a heating rate of $20^{\circ} \mathrm{C} / \mathrm{min}$ and kept at this temperature for $5 \mathrm{~min}$; afterwards, the samples were cooled from $220^{\circ} \mathrm{C}$ to $40{ }^{\circ} \mathrm{C}$ (1st cooling) at a cooling rate of $20^{\circ} \mathrm{C} / \mathrm{min}$ and then heated from $40^{\circ} \mathrm{C}$ to $200{ }^{\circ} \mathrm{C}$ (2nd heating) at a heating rate of $20^{\circ} \mathrm{C} / \mathrm{min}$. A second set of experiments was carried out on 5-10 $\mathrm{mg}$ samples under nitrogen atmosphere (nitrogen flow was $50 \mathrm{~mL} / \mathrm{min}$ for all experiments) by using a Perkin-Elmer DSC-4000 differential scanning calorimeter thermal analyzer equipped with a 3 stage cooler able to reach $-130{ }^{\circ} \mathrm{C}$. Previously, the instrument was calibrated by using indium (m.p. $156.6^{\circ} \mathrm{C}, \Delta H_{\mathrm{m}}=28.5 \mathrm{~J} / \mathrm{g}$ ) and zinc (m.p. $419.5^{\circ} \mathrm{C}$ ). MDs, PLA/CHROs, and PLA/MDs were heated from 20 to $180^{\circ} \mathrm{C}$ at $10^{\circ} \mathrm{C} / \mathrm{min}$ (1st heating), taken at $180^{\circ}$ for $2 \mathrm{~min}$, cooled to $-90^{\circ} \mathrm{C}$ at the same scan rate (1st cooling), taken at $-90^{\circ} \mathrm{C}$ for $2 \mathrm{~min}$, and then heated again to $180^{\circ} \mathrm{C}$ at $10^{\circ} \mathrm{C} / \mathrm{min}$ (2nd heating). Glass transition temperature $\left(T_{\mathrm{g}}\right)$, melting temperature $\left(T_{\mathrm{m}}\right)$, melting enthalpy $\left(\Delta H_{\mathrm{m}}\right)$, cold crystallization temperatures $\left(T_{\mathrm{cc}}\right)$, cold crystallization enthalpy $\left(\Delta H_{\mathrm{cc}}\right)$, and percent of crystallinity were determined from the 2 nd heating thermogram. Percent of crystallinity was determined on the basis of the following equation: $\mathrm{C} \%=\left(\left(\Delta H_{\mathrm{m}}-\Delta H_{\mathrm{cc}}\right) / \Delta H_{\mathrm{m}}{ }^{0}\right) \times 100$, with $\Delta H_{\mathrm{m}}=$ enthalpy associated with the melting process (when a multimodal melting peak is present, its total area is used), $\Delta H_{\mathrm{cc}}=$ enthalpy associated with the cold crystallization process, and $\Delta H_{\mathrm{m}}{ }^{0}$ is the enthalpy associated with the melting process of $100 \%$ crystalline PLA $(93.1 \mathrm{~J} / \mathrm{g})[17,18]$.

UV-Visible absorption spectra were recorded with a Perkin-Elmer Lambda 65 spectrophotometer. Spectra were acquired from polymer films or solutions. The concentration of the solutions was chosen in order to maintain absorbance near 1 . The concentrations of free chromophores in $\mathrm{CHCl}_{3}$ were $2.35 \times$ $10^{-5} \mathrm{M}(\mathrm{CA}), 4.50 \times 10^{-5} \mathrm{M}(\mathrm{FM})$, and $2.35 \times 10^{-5} \mathrm{M}(\mathrm{DR})$. The concentrations of free chromophores in $\mathrm{EtOH} 95 \%$ were $2.27 \times 10^{-5} \mathrm{M}(\mathrm{CA}), 3.73 \times 10^{-5} \mathrm{M}(\mathrm{FM})$, and $1.58 \times 10^{-5} \mathrm{M}$ (DR). Chloroform solutions of MDs were prepared by dissolving a known quantity of solid MD in a known volume of solvent in order to have absorbance near 1. Chloroform solutions of MD had the following compositions: 0.228 $\mathrm{mg} / \mathrm{mL}$ (MDCA5), $0.116 \mathrm{mg} / \mathrm{mL}$ (MDFM5), and $0.110 \mathrm{mg} / \mathrm{mL}$ (MDDR5). 
Fluorescence emission and excitation spectra were acquired under isotropic excitation with a Perkin Elmer luminescence spectrometer LS55 controlled by FL Winlab software and equipped with the front-surface accessory. Origin 7.5, software by Microcal Origin ${ }^{\circledR}$, was used for analysis of the absorption and emission data. Some fluorescence emission spectra were collected by a FluoroMax4-TCSPC fluorometer with a xenon lamp as the excitation source. Chloroform solutions and polymer films were analyzed. In the case of film, steady-state fluorescence spectra of polymer films were acquired at room temperature under isotropic excitation by placing the solid sample holder at $30^{\circ}$ with respect to the incident beam with the aim to focus the excitation light at the front surface of the samples so that fluorescence emission was collected from the same region, minimizing reflected and scattered light. The Fluorescence Excitation-Emission Map (EEM) was collected by a FluoroMax4-TCSPC fluorometer with a xenon lamp as the excitation source. The EEM spectrum was a collection of a series of emission spectra over a range of excitation wavelengths. In this experiment, the EEM spectrum was collected with subsequent scanning emission spectra from 340 to $450 \mathrm{~nm}$ at 2-nm increments by varying the excitation wavelength from 230 to $340 \mathrm{~nm}$ at 4 -nm increments.

\section{Results and Discussion}

\subsection{Macromolecular Dyes (MDs)}

\subsubsection{Preparation, Structural Characterization, and Thermal Properties}

The preparation of MDs was carried out by ring open polymerization (ROP) of L-lactide catalyzed by $\mathrm{Sn}(\mathrm{Oct})_{2}$ in the presence of the co-initiators described in the Introduction. The ratio between the co-initiator and L-lactide was modulated in order to obtain MDs with different molecular weights. Low final molecular weights of MDs were decided upon because this can simplify their characterization and can emphasize the relation between initiator and polymer properties. The formation of PLA by polymerization of L-lactide was verified by comparing the FT-IR spectra of L-lactide and of MDs (Figure S2 and Table S2, Supplementary Materials) [19]. The conversion of L-lactide into MDs was evaluated gravimetrically after purification of the sample, and it was high quantitatively when FM and CA were employed as co-initiators. In the presence of DR, a significantly lower conversion was obtained possibly due to the steric hindrance of the dye hampering the catalyst activity (Table 1). ${ }^{1} \mathrm{H}-\mathrm{NMR}$ spectra of MDs (Figure 2 for sample MDCA10 and Figures S3 and S4, Supplementary Materials, for samples MDFM5 and MDDR5) were recorded to identify the initiator and to evaluate PD, which is the number of lactic acid repeating units in the polymer (see Section 2.2 and Table 1). The amount of unreacted lactide was quantitatively evaluated by ${ }^{1} \mathrm{H}-\mathrm{NMR}$ (see Section 2.2 and Figure S1, Supplementary Materials), and about 2-3 wt.\% of L-lactide was still present at the end of the reaction because equilibrium between polymerization and depolymerization processes can occur at high temperatures $[20,21] .{ }^{1} \mathrm{H}-\mathrm{NMR}$ analysis was used also to evaluate the absence of residual free chromophores (see Section 2.2). PD values evaluated by ${ }^{1} \mathrm{H}-\mathrm{NMR}$ were lower than expected (Table 1) on the basis of conversion but, as discussed later in the text, some side reactions that lowered the PD probably occurred during polymerization.

Purified samples were analyzed by SEC; the chromatogram curves show a main peak associated to elution of MDs and some other peaks eluting at longer retention time (i.e., low molecular weight fractions) (Figure 3a for MDCA and Figure S5 Supplementary Materials for other MDs). Elution of unconverted lactide, oligomers containing two or three lactic acid units, or the unreacted initiator can account for these peaks [22]. The molecular weight distribution curves of the main peak, especially for low molecular weight MDs, are bimodal or multimodal (Figure $3 b$ for MDCA), giving a dispersity higher than 1 . The comparison of Mn obtained by SEC with that calculated by considering the PD determined by ${ }^{1} \mathrm{H}-\mathrm{NMR}$ (Table 1 ) shows some discrepancies that are probably due to a bias introduced by PS-based SEC calibration. Indeed, differences in hydrodynamic volume and molecular masses between polystyrene and PLA can exist [15]. This discrepancy can be partially compensated by multiplying SEC data for the Mark-Houwink factor of 0.58 [12]. From the SEC evaluation of Mn, a clear 
trend can be observed, and as expected, molecular weight is higher when the amount of co-initiator (the chromophore) is lower.

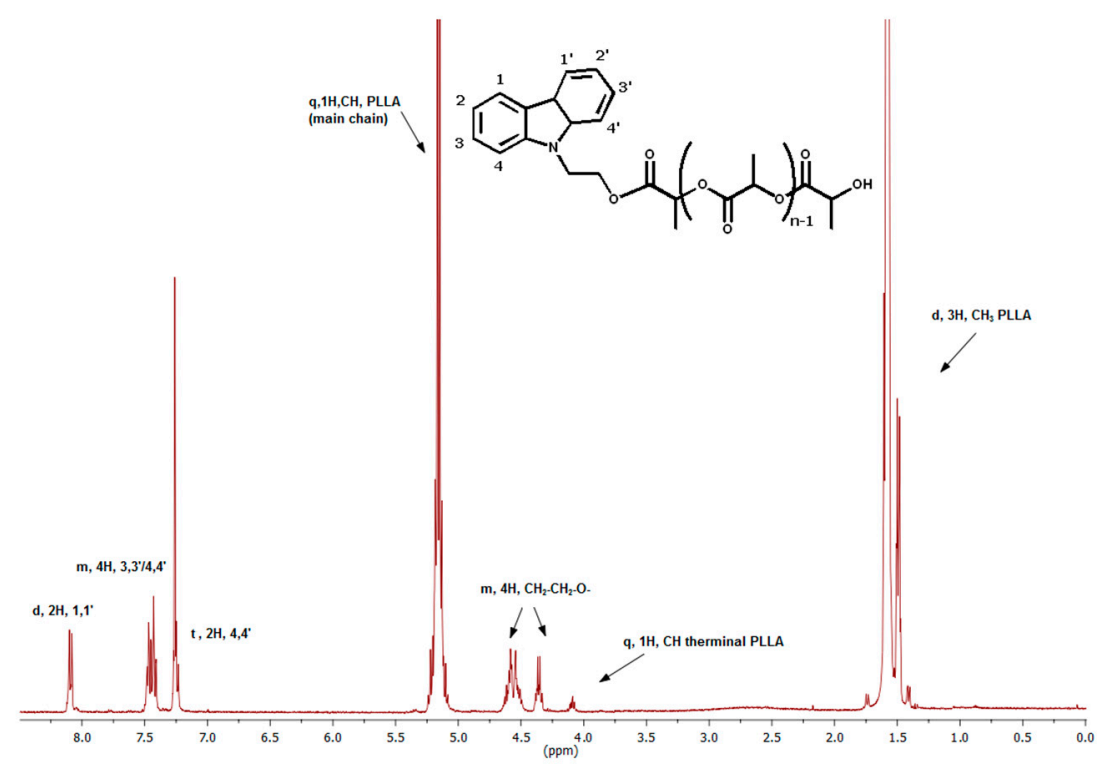

Figure 2. Proton nuclear magnetic resonance ${ }^{1} \mathrm{H}-\mathrm{NMR}$ spectrum of macromolecular dye (MD) prepared by using $10 \mathrm{~mol} \%$ of $9 \mathrm{H}$-carbazol-ethanol (CA) (MDCA10) $\left(\mathrm{CDCl}_{3}\right)$.

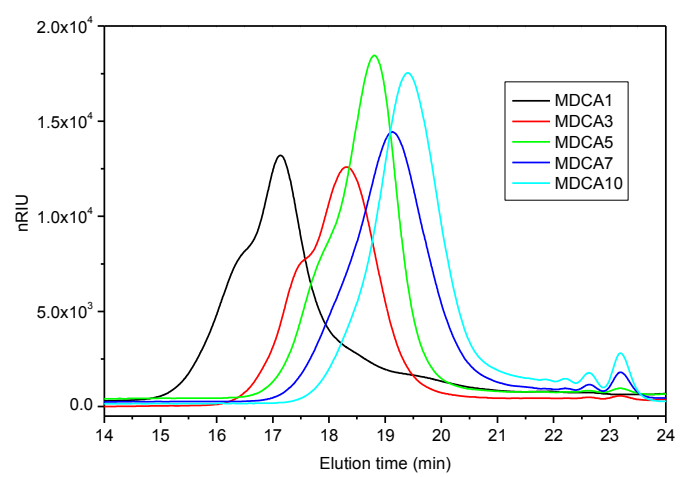

(a)

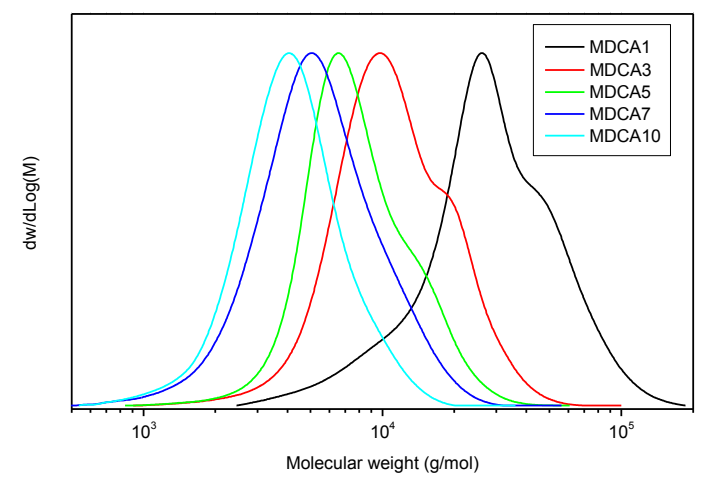

(b)

Figure 3. (a) Chromatograms collected during size exclusion chromatography (SEC) analysis of MDs prepared by using 1-10 mol\% of CA (MDCA1-MDCA10) and (b) molecular weight (MW) distribution of samples MDCA1-MDCA10: the curves are normalized to the maximum value.

The multimodality of the chromatography peaks as well as the presence of species having low molecular weight can be due to multiple factors. For example, in the living polymerization of lactide catalyzed by $\mathrm{Sn}(\mathrm{Oct})_{2}$, dispersity can diverge from unity when the reaction is carried out in bulk because of the presence of transesterification and, in particular, intermolecular transesterification reactions that are generally responsible for the enlargement of molecular weight distribution [23-25]. By this mechanism, an active chain end (i.e., metal alkoxide terminated) of a growing macromolecule can attack an ester bond internal to another polymer chain in place of the ester bond of L-lactide. By this way, the number of active and dormant chains (i.e., alcohol terminated) is the same but their length is different (Scheme S1, Supplementary Materials). Furthermore, transesterification reactions are found to be more active when a low concentration of alcohol (co-initiator) is used in the ROP and, in this case, the dispersity approached the value of 2. Conversely, at a high concentration of $\mathrm{ROH}$ (co-initiator), the role of transesterification was reduced $[24,25]$. The presence of traces of water can also justify the multimodality of SEC curves because water can act as co-initiator of ROP like 
alcohols [7]. Multimodal distribution of the MW can also result from solidification of high molecular weight PLAs that formed during the reaction at $130{ }^{\circ} \mathrm{C}$. This can cause inhomogeneous magnetic stirring and poor temperature control that can give side reactions. This cannot occur for low molecular weight PLAs which remain viscous liquids at $130{ }^{\circ} \mathrm{C}$. Finally, in the case of DR, its melting point is close to the reaction temperature and this can prevent complete dissolution and limit homogeneous distribution inside the reaction mixture. Consequently, lower conversion of L-lactide and peaks eluting at high retention time in SEC chromatograms are observed (Figure S5b, Supplementary Materials).

Thermal properties of MDs were assessed by DSC analysis (Table S3, Supplementary Materials). First and second heating scans were analyzed because different information can be deduced by the analysis of the two curves (MDCA: Figure 4 and Figures S6 and S7, Supplementary Materials, for the other MDs). The absence of a crystallization exotherm peak (related to cold crystallization, $T_{\mathrm{cc}}$ ) in the first hating scan provides evidence of the complete crystallinity of the samples (Figure $4 \mathrm{a}$ and Figures S6a and S7a, Supplementary Materials). The only exception is sample MDFM1, where an exothermic peak $\left(T_{\mathrm{cc}}\right)$ at about $84^{\circ} \mathrm{C}$ was observed (Figure S6a, Supplementary Materials). Melting temperature, melting enthalpy, and crystallinity increase with the increase of the molecular weight of MDs and depend on the quantity of chromophores used in the feed (Table S3, Supplementary Materials). The correlation between molecular weight and thermal transitions of PLA was reported for PLA samples having Mn lower than $50-100 \mathrm{Kg} / \mathrm{mol}$ and is related to the fact that a better packing can be obtained for longer polymer chains than for shorter ones [17,26-28]. Moreover, the presence of large and sterically hindered end groups in low molecular weight PLA can influence $T_{\mathrm{m}}$ values, and a decrease of $T_{\mathrm{m}}$ was observed by increasing the dimension of the end group [27]. This can be due to the difficult packaging of the polymer chains in an ordered structure. In some cases, a bimodal melting peak or two separated melting peaks were present. This can be associated with the formation of two crystal forms of PLA: the $\alpha$ and $\alpha^{\prime}$ crystals that have different thermal stability and consequently different melting temperatures. The second heating thermograms (Figure $4 \mathrm{~b}$ and Figures S6b and S7b, Supplementary Materials) of samples having higher molecular weight showed an exothermic peak between 98 and $120^{\circ} \mathrm{C}$ due to cold crystallization phenomenon $\left(T_{\mathrm{cc}}\right)$ and an endothermic peak due to melting of the polymer at $130-160{ }^{\circ} \mathrm{C}$. The typical PLA cold crystallization process that is absent in the first heating scan can be associated to the formation of irregular crystals that occurs during the heating process. The presence of $T_{\mathrm{cc}}$ in the second heating scan proves that, despite the low molecular weight of MDs, the samples have no time to crystallize during cooling, giving an amorphous state. The $T_{\mathrm{cc}}$ value depends on different factors like the molecular weight of the samples and the presence of hindered groups that can slow down the crystallization process. However, $T_{\mathrm{cc}}$ values of MDs do not follow a predictable evolution probably because of the concurrence of too many parameters. The melting temperatures recorded during the second heating were lower than those of the first heating probably due to the formation of less ordered crystals (the $\alpha^{\prime}$ form). No cold crystallization or melting processes were instead observed in the second heating scan of MD10s (prepared by using $10 \mathrm{~mol} \%$ of chromophores). Probably the presence of the hindered end group and the relatively low molecular weight of MD10s prevent the crystallization process. Finally, in each sample, the enthalpy associated with the cold crystallization process and with the melting was similar, suggesting that crystals formed at $T_{\mathrm{cc}}$, melted at $T_{\mathrm{m}}$ (Table S3, Supplementary Materials).

DSC analysis was repeated on the MDs prepared by using $5 \mathrm{~mol} \%$ of chromophores as co-initiators. The samples were analyzed by using a heating/cooling rate of $10{ }^{\circ} \mathrm{C} / \mathrm{min}$ in a large temperature range with the aim to detect glass transition temperature (Figure S8 and Table S4, Supplementary Materials). As expected, the use of the slower heating/cooling rate in collecting data determined the shift to lower temperatures of the main thermal transition of the samples; however, despite the thermal shift, the same transitions were observed [29]. Glass transition temperatures were in the expected thermal range considering the molecular weight of the analyzed samples. 


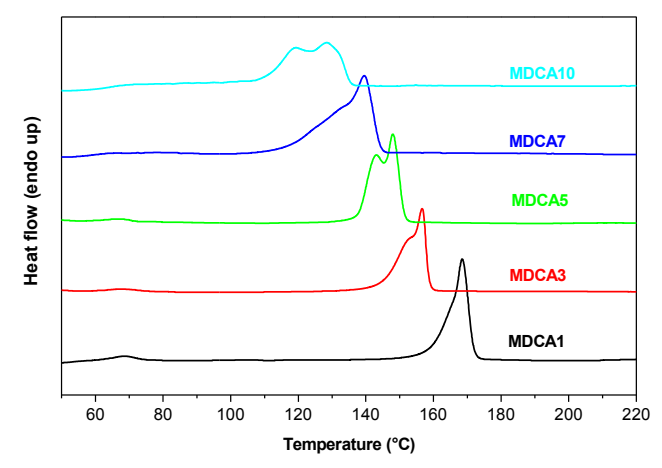

(a)

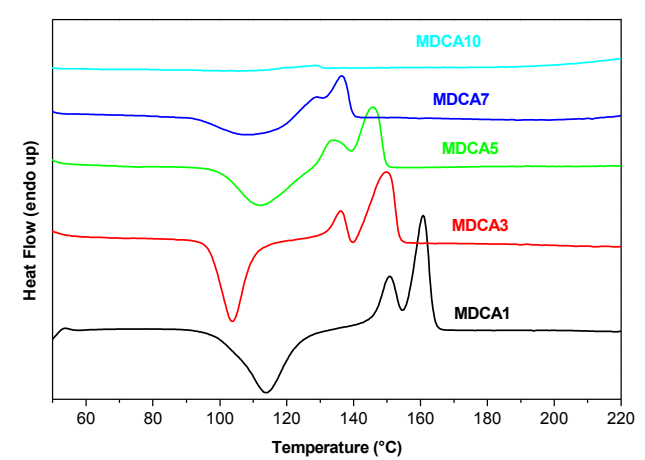

(b)

Figure 4. Differential scanning calorimetry (DSC) curves of the first heating (a) and second heating (b) scans of samples MDCA1-MDCA10: the curves are vertically shifted for clarity.

\subsubsection{Photophysical Properties of MD5s}

With the aim to highlight potential photophysical differences between free chromophores and MDs, UV-Vis absorption spectra of MD5s (prepared by using $5 \mathrm{~mol} \%$ of co-initiator) were compared with those of the free co-initiators (Figure 5). All the samples were dissolved in chloroform (see concentration in Section 2.5).

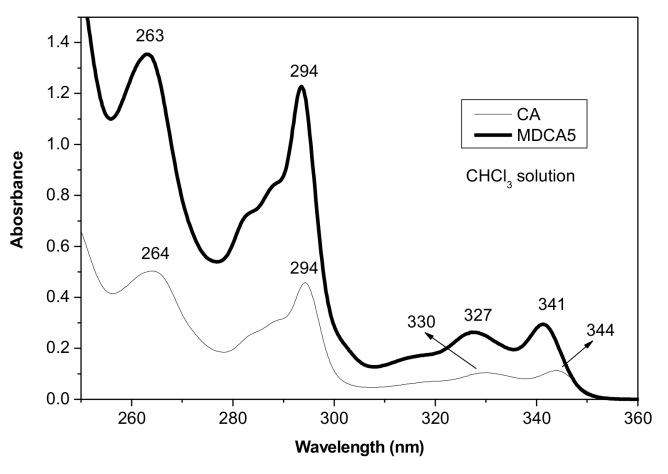

(a)

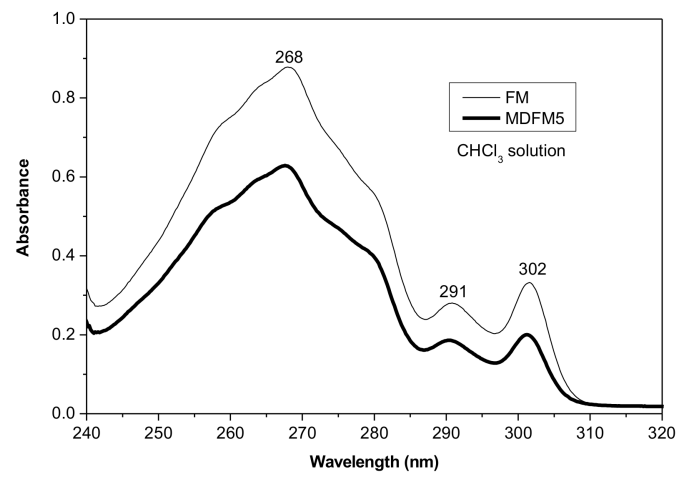

(b)

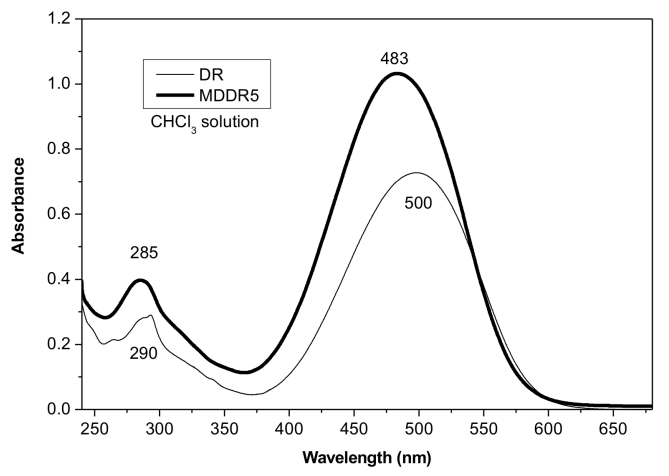

(c)

Figure 5. Ultraviolet-visible (UV-vis) absorption spectra in chloroform solution of (a) CA and MDCA5, (b) 9-fluorenyl-methanol (FM) and MD prepared by using $5 \mathrm{~mol} \%$ of FM (MDFM5), and (c) 2-(4-(2-chloro-4-nitrophenylazo)-N-ethylphenylamino)ethanol (DR) and MD prepared by using 5 mol\% of DR (MDDR5): see Section 2.6 for concentrations.

In the UV-Vis absorption spectrum of MDCA5, a very small blue shift of about $3 \mathrm{~nm}$ of the band at $344 \mathrm{~nm}$ was observed with respect to CA (Figure 5a) [30]. This shift was probably due to the formation 
of the ester bond between CA and PLA [31]. Instead, the spectra of MDFM5 and FM showed the same absorption maxima (Figure 5b), and these are in agreement with the data reported in the literature [32,33]; no effects of the presence of the PLA chain substituted to the carbon atom in the position 9 were observed. In the case of MDDR5, a blue shit of $17 \mathrm{~nm}$ with respect to the absorption band of DR was observed (Figure 5c). This hypsochromic shift could be attributed to the conversion of hydroxyl group in the original dye into the stronger electron-withdrawing ester linkage formed by ROP [34]. By the calibration curves method, the molar extinction coefficient at the absorption maxima of each chromophore was determined (Table S5, Supplementary Materials). These values were used to evaluate the real amount of chromophore present in MDs by measuring the absorbance of chloroform solutions of MDs at known concentrations (Table S1, Supplementary Materials) and by assuming that the molar extinction coefficient of chromophore does not vary after formation of the bond with PLA. From this evaluation, it is observed that, in the case of MDFM5 and MDCA5, about $5 \mathrm{wt} . \%$ of chromophores were present in each sample whereas MDDR5 contained about $10 \mathrm{wt} . \%$ of DR. All these values were slightly lower than the theoretical ones calculated on the basis of the polymerization feed, and this could be due to a possible loss of chromophores during polymerization and purification.

Fluorescence emission spectra of CA and FM were collected from chloroform solution and were compared to the emission spectra of MDCA5 and MDFM5 in chloroform (Figure 6). DR is a non-emitting molecule, and therefore, DR and MDDR5 are not analyses.

CA and MDCA5 show emission spectra with a vibration structure of the emission band that is very similar to that reported in the literature $[31,35,36]$. In the spectral region between 300 and $350 \mathrm{~nm}$, the emission spectra of CA and MDCA5 are mirror images of the corresponding absorption spectra. The Stokes shift is $4 \mathrm{~nm}$ in the case of CA and $7 \mathrm{~nm}$ in the case of MDCA5 (Figure 6a). This difference is probably due to a very small change of carbazoyl geometry due to the presence of PLA chain. Alternatively, different solvation of the steady state and the excited state of CA and MDCA5 associated with the presence of PLA chain could cause the differences in the Stokes shift values. No emission attributable to excimer formation was detected; therefore, carbazolyl moieties in CA or MDCA5 were not interacting with each other. FM and MDFM5 showed similar emission spectra, and both are very similar to that reported for fluorene $[37,38]$, suggesting that the presence of the methanol group or the PLA chain in position 9 of the molecule does not interfere with the emission properties of chromophore. Again, no band attributable to excimer formation was detected (Figure 6b) [33].

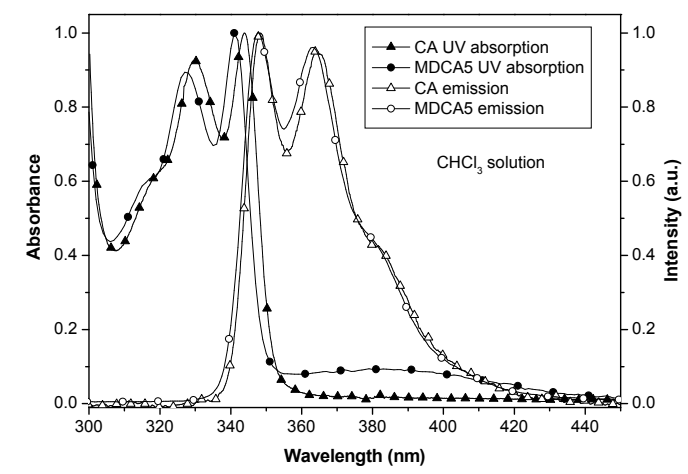

(a)

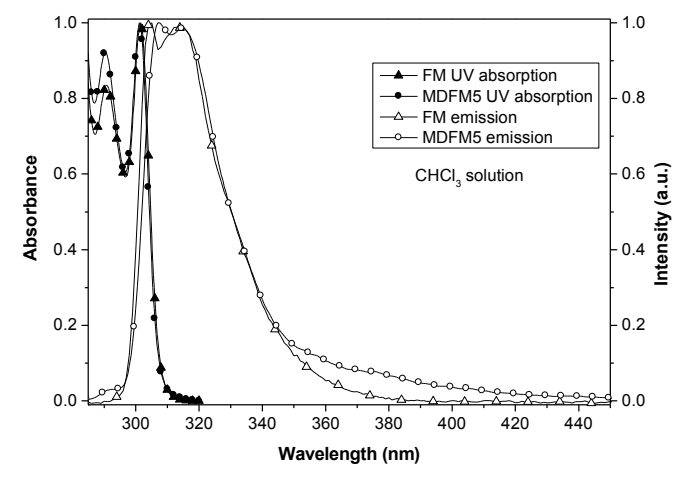

(b)

Figure 6. UV-Vis absorption and fluorescence emission spectra: (a) CA and MDCA5 in $\mathrm{CHCl}_{3}$, $\lambda_{\text {exc }}=290 \mathrm{~nm}$, and (b) FM and MDFM5 in $\mathrm{CHCl}_{3}, \lambda_{\text {exc }}=270 \mathrm{~nm}$. Spectra are normalized to absorption and emission maximum, respectively.

From the data so far discussed, it is evident that MDs have photophysical properties that are very similar to those of the free chromophores; therefore, their use as co-initiators in the ROP of L-lactide does not modify their photophysical properties that are successfully transferred to the polymer matrix. 


\subsection{Blending of MDs with Commercial PLA}

\subsubsection{Preparation, Structural Characterization, and Thermal Properties of the Blends}

As discussed in the Introduction, the preparation of dyed PLA could be very interesting to obtain new materials having applications in different sectors. One of the main issues associated with mixing of low molecular weight additives to polymer is their migration and leaching especially during the service life of the materials. To limit the loss of additives, the use of molecules having high molecular weight is largely reported and used in the industry. Another key parameter to take into account for the design of polymer additives is the surface energy involved in the polymer-additive interaction. Ideally, the interaction between additives and polymer matrix should be strong to minimize surface energy. Interestingly, the use of MDs as additives satisfies both requirements: MDs are, indeed, chromophores with long PLA chains that increase their molecular weight, lowering their volatility, and the presence of PLA chain can reduce the surface energy of the additives, thus favoring their dispersion. Accordingly, mixing of MDs with commercial PLA can produce stable and homogeneous dispersion of the chromophores into the PLA matrix, limiting also their leaching. Similar methods are also reported in the field of dyeing PLA fibers or tissue, where it is demonstrated that ad hoc modified commercial dyes having a high affinity for the polymer have better dying properties than unmodified dyes [39].

From the previously described MDs, those containing about $5 \mathrm{~mol} \%$ of chromophores (MD5s) are chosen and mixed to high molecular weight PLA. For comparison, PLA was melt-mixed with free chromophores that were added in an amount equivalent to that present in PLA/MD blends calculated on the basis of the data reported in Table S1 (Supplementary Materials) (the new samples were coded PLA/CHROs, and in particular PLA/CA, PLA/FM, and PLA/DR were prepared).

SEC analysis of PLA/MDs showed a main elution peak due to PLA, and only in the case of PLA/MDDR5, there was a small peak eluting at a higher retention time, attributable to MDs (Figure S9, Supplementary Materials). DSC analyses of PLA/MDs and of PLA/CHROs showed that $T_{\mathrm{g}}$ and $T_{\mathrm{m}}$ of PLA/MDs and of PLA/CHROs were very similar to that of neat PLA (Table 2 and Figure S10, Supplementary Materials). $T_{\mathrm{g}}$ was about $59^{\circ} \mathrm{C}$, whereas $T_{\mathrm{m}}$ was about $150{ }^{\circ} \mathrm{C}$, and in all cases, two melting peaks or bimodal melting peaks were detected. $T_{\mathrm{cc}}$ of PLA/MDs was slightly higher than that of PLA and of PLA/CHROs. Probably, in the case of PLA/MDs, the presence of a low molecular weight PLA end capped with sterically hindered group slowed down the crystallization of the matrix causing the shift of the crystallization process to a higher temperature. Finally, the crystallinity of all the samples was quite low, suggesting that the chains that crystallize at $T_{\mathrm{cc}}$ melt at $T_{\mathrm{m}}$.

Table 2. Differential scanning calorimetry (DSC) data ${ }^{1}$ of poly(lactic acid) (PLA), PLA mix with free chromophores (PLA/CHROs), and PLA mixed with MDs (PLA/MDs).

\begin{tabular}{|c|c|c|c|c|c|c|}
\hline Sample & $\begin{array}{c}T_{\mathrm{g}} \\
\left({ }^{\circ} \mathrm{C}\right)\end{array}$ & $\begin{array}{c}T_{\mathrm{cc}} \\
\left({ }^{\circ} \mathrm{C}\right)\end{array}$ & $\begin{array}{c}\Delta H_{\mathrm{cc}} \\
(\mathrm{J} / \mathrm{g})\end{array}$ & $\begin{array}{c}T_{\mathrm{m}} \\
\left({ }^{\circ} \mathrm{C}\right)\end{array}$ & $\begin{array}{c}\Delta H_{\mathrm{m}} \\
(\mathrm{J} / \mathrm{g})\end{array}$ & $\begin{array}{c}\text { Cryst. }^{2} \\
(\%)\end{array}$ \\
\hline PLA & 57.5 & 113.7 & -2.2 & 149.5 & 3.4 & 3.7 \\
\hline PLA/CA & 58.9 & 114.2 & -31.6 & $\begin{array}{l}149.9 \\
156.2\end{array}$ & 32.9 & 1.5 \\
\hline PLA/FM & 59.1 & 114.9 & -32.6 & $\begin{array}{l}150.2 \\
156.6\end{array}$ & 32.4 & - \\
\hline PLA/DR & 58.3 & 131.0 & -13.7 & 153.3 & 17.6 & 4.0 \\
\hline PLA/MDCA5 & 58.8 & 119.5 & -32.9 & 151.2 & 32.7 & - \\
\hline PLA/MDFM5 & 58.8 & 119.5 & -33.7 & 152.0 & 32.1 & - \\
\hline PLA/MDDR5 & 59.2 & 120.1 & -30.9 & 151.3 & 37.6 & 7.2 \\
\hline
\end{tabular}

${ }^{1}$ Heating and cooling scans were carried out at $10{ }^{\circ} \mathrm{C} / \mathrm{min} .{ }^{2}$ Crystallinity was evaluated on the 2 nd heating scan by considering the enthalpy associated with the melting process of $100 \%$ crystalline PLA $=93.1 \mathrm{~J} / \mathrm{g}[17,18]$. 


\subsubsection{Photophysical Properties of the Blends}

The photophysical properties of PLA/MDs were compared to those of PLA/CHROs with the aim to show the differences between the addition of free chromophores or of MDs to PLA (Figure 7). Photophysical properties of the blends were studied by collecting UV-Vis absorption and fluorescence emission spectra from polymeric films. Absorption spectra and maxima of the samples obtained by mixing CA, MDCA5 (Figure 7a), FM, and MDFM5 (Figure 7b) with PLA were the same as that already observed in the analysis of the chloroform solution of the chromophores and of MDs. Therefore, the presence of PLA does not alter the absorption properties of the pure chromophores and of MDs; in addition, on passing from the solution to the polymer film, no variations of the absorption spectra ware observed. Instead, a bathochromic shift of about $7 \mathrm{~nm}$ was observed in the spectra of DR and MDDR5 when they were mixed with PLA (Figure 7c). This effect, that is not due to the formation of aggregates, because the aggregate formation generally causes a hypsochromic shift [40], can be attributed to solvatochromism, a characteristic feature of disperse red derivatives. Generally, on passing from low to high dielectric constant solvents, a red shift (positive solvatochromism) of the main band was observed [41]. The spectrum of DR recorded in EtOH 95\% (Table S5, Supplementary Materials) showed an absorption maximum at $507 \mathrm{~nm}$ that is $24 \mathrm{~nm}$ red shifted with respect to the spectrum recorded in chloroform (Table S5, Supplementary Materials), confirming that solvatochromism can occur also for DR. Although it is generally difficult to compare the photophysical properties of chromophores in solution or embedded in a polymer matrix, the red shift of MDDR5 and of DR mixed with PLA could be attributed to the solvatochromic effect played by the PLA matrix. Indeed, disperse red 1, a chromophore similar to DR, shows a similar bathochromic shift when it is embedded in polymer matrices having different polarity [42].

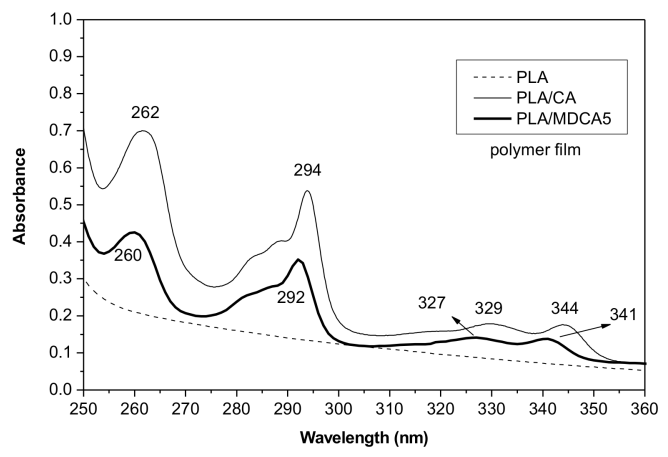

(a)

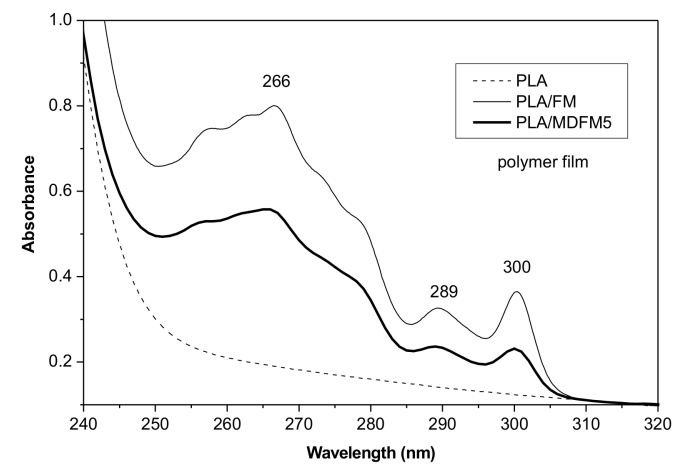

(b)

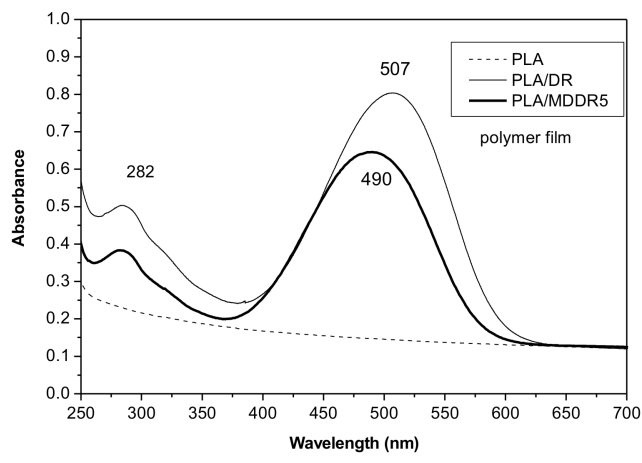

(c)

Figure 7. UV-vis absorption spectra were collected from polymeric film: (a) poly(lactic acid) (PLA), PLA mixed with CA (PLA/CA), and PLA mixed with MDCA5 (PLA/MDCA5); (b) PLA, PLA mixed with FM (PLA/FM), and PLA mixed with MDFM5 (PLA/MDFM5); and (c) PLA, PLA mixed with DR (PLA/DR), and PLA mixed with MDDR5 (PLA/MDDR5). 
Fluorescence emission spectra of the polymer blends were recorded on polymeric films. Again, PLA/MDDR5 and PLA/DR do not show fluorescence emissions, and for this reason, they were not analyzed. The emission spectra of PLA/CHROs and PLA/MDs (Figure 8a,b) were similar to those recorded in solution (Figure 6a,b). However, in the case of the sample containing MDCA, an attenuation of the intensity of the $0-0$ band (at about $350 \mathrm{~nm}$ ) was observed. This self-absorption effect, already observed in the literature, is attributed to the formation of aggregates $[31,35,36]$ that however does not produce excimers since no emission is observed at longer wavelengths. These data suggest that MDs and free chromophores are well dispersed in the amorphous phase of the PLA matrix and that they are not interacting with each other because no aggregate emission was observed. Moreover, the photophysical properties of MDs were completely transferred to PLA films.

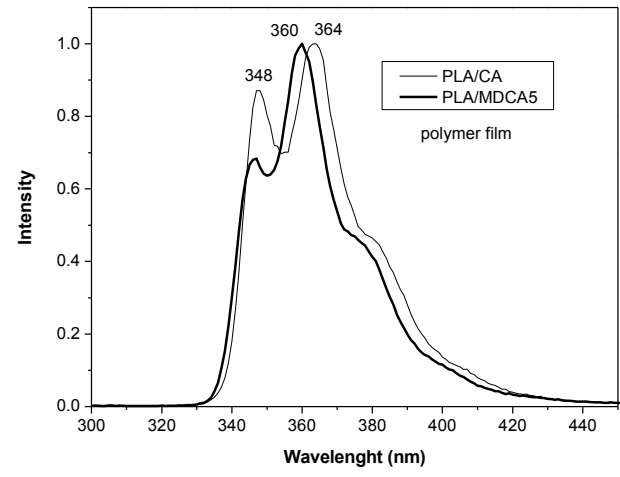

(a)

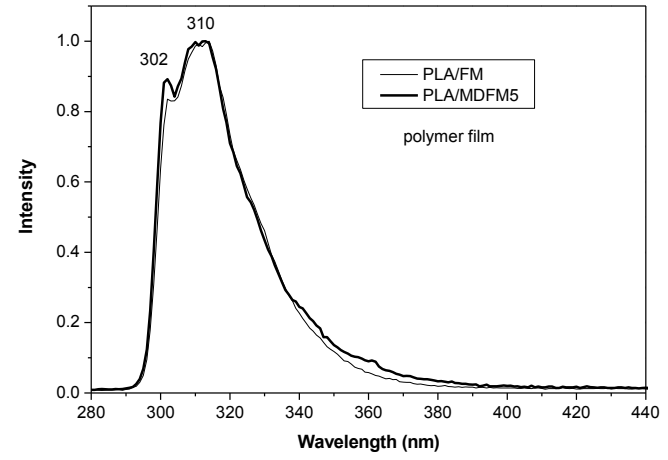

(b)

Figure 8. Fluorescence emission spectra of (a) PLA/CA and PLA/MDCA5, $\lambda_{\operatorname{exc}}=290 \mathrm{~nm}$, and (b) PLA/FM and PLA/MDFM5, $\lambda_{\text {exc }}=270 \mathrm{~nm}$ : Spectra are collected from polymer film and are normalized to emission maximum.

Interestingly, PLA/MDCA5 and PLA/MDFM5 have strong absorption bands in the UV-A and UV-B regions whereas they are transparent to visible light, making the film transparent and the dye invisible to the naked eye. This suggests the use of these materials as films for food packaging; indeed, they can protect food from dangerous UV radiation and the packaged goods can be visually observed. Moreover, the UV-A- and UV-B-protecting ability of these MDs can be useful in the production of UV-protecting garments. Furthermore, PLA/MDCA5 and PLA/MDFM5 are fluorescent and, in the case of PLA/MDCA5 its fluorescence emission can be evidenced if it is irradiated with Wood's lamp emitting at $254 \mathrm{~nm}$ (Figure 9). This feature, together with the fact that CA is invisible to the naked eye, can be exploited in the production of track devices for tracing goods along their distribution chain or for anti-counterfeit purposes.
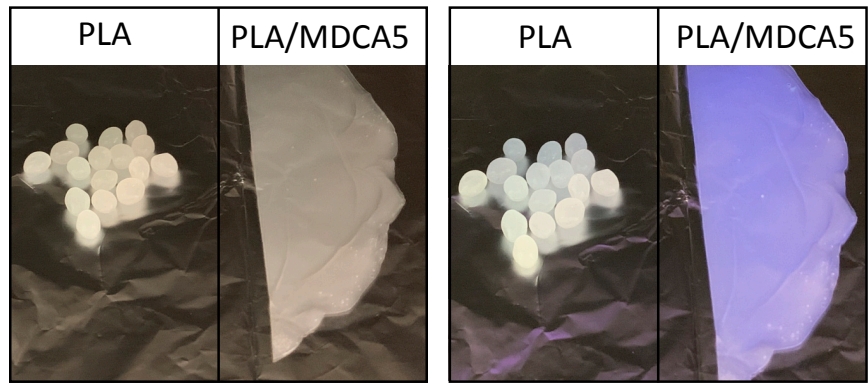

Figure 9. PLA and PLA/MDCA5 under natural light (left) and under UV light $(\lambda=254 \mathrm{~nm})$ (right).

\subsection{Migration Tests}

Two different migration tests were performed: the first set was carried out by suspending the polymer films in a suitable solvent, and the latter was carried out in the solid phase. 
Migration in solution was carried out in $\mathrm{EtOH} \mathrm{95 \%} \mathrm{because} \mathrm{it} \mathrm{is} \mathrm{already} \mathrm{used} \mathrm{to} \mathrm{check}$ the migration of antioxidants from PLA nanocomposite films [43] and it is considered a fat simulant in the determination of species that can be released by migration from food contact polymer films such as PLA [22]. By considering that free chromophores and MDs are soluble in this solvent, $\mathrm{EtOH} 95 \%$ is considered a useful solvent for our purposes.

The EtOH solutions, where different PLA samples were suspended, were analyzed by UV-Vis spectroscopy after $90 \mathrm{~min}$ of contact. Since chromophores used in this paper show solvatochromic features, UV-Vis spectra of the free chromophores were recorded in EtOH 95\% (Table S5, Supplementary Materials, for absorption wavelengths values and molar extinction coefficients at absorption maxima). The results obtained after migration experiments reported in Table 3 (see Section 2.5 for details) evidence that, as expected, a higher quantity of the chromophores was extracted from PLA/CHROs than from PLA/MDs. In the case of films containing MDDR5 and DR, migration tests were carried out also for $3.5 \mathrm{~h}$. The total amount of extracted DR was $35 \mathrm{wt} . \%$ with respect to the total amount of DR from PLA/DR and less than $5 \mathrm{wt} . \%$ from PLA/MDDR5. This result showed that the few chromophores were lost by PLA/MDDR5 during the first $1.5 \mathrm{~h}$ of contact, whereas in the case of PLA/DR, a considerable migration of DR was still going on after $3 \mathrm{~h}$.

Table 3. Amount ${ }^{1}$ of chromophore extracted from PLA mixed with free chromophores (PLA/CHROs) and PLA/MDs.

\begin{tabular}{ccc}
\hline Chromophore & $\begin{array}{c}\text { PLA/CHROs } \\
\text { (wt. } \%)\end{array}$ & $\begin{array}{c}\text { PLA/MDs } \\
\text { (wt. } \%)\end{array}$ \\
\hline CA & 40 & 9 \\
FM & 74 & 8 \\
DR & 28 & 4 \\
\hline 1
\end{tabular}

Taking inspiration from the textile industry, where the leaching of dyes from fabric is a very important issue because it can occur during processing steps and the service life of the garment, we were intrigued by the possibility to qualitatively test the transfer of free chromophores or MDs from PLA films to another polymer. This can be considered an alternative method to evidence the migration of a dye embedded in a polymer matrix. Indeed, only when the chromophore is free to migrate (not covalently bonded to the polymer backbone or immobilized) and its affinity is higher for another polymer than for PLA could we observe the transfer of color from PLA to another material. In particular, we carried out some experiments by putting dyed PLA films in contact with two different polymer films. To better evidence the staining, i.e., the transfer of color from PLA to anther polymer, PLA/DR and PLA/MDDR were used because DR absorbs in the visible portion of the electromagnetic spectrum and can be easily detected. Considering the molecular structure of DR, it is possible to hypothesize its good chemical affinity for polymers having aromatic groups like polystyrene (PS) and poly(ethylene terephthalate) (PET). In this work, PET and styrene-butadiene copolymer (SBC), which is more flexible than pure PS, were used. To speed up the process, the experiment was carried out in a hot press where films of PLA/DR and PLA/MDDR were compressed on PET films at $130{ }^{\circ} \mathrm{C}$ for $30 \mathrm{~min}$ (Figure 10a). The experiment was repeated by compressing dyed PLA films on SBC films at $100{ }^{\circ} \mathrm{C}$ or at $120^{\circ} \mathrm{C}$ for 30 min (Figure 10b).

From the pictures reported in Figure 10a,b, it is evident that staining of PET or SBC is observed only for the PLA/DR sample, suggesting that DR has a higher affinity for PET and SBC than for PLA. As expected, MDDR has a lower migration ability than DR. These findings definitely assessed that, once embedded in PLA, MDDR is less susceptible to leaching than DR and that the immobilization of DR in MDDR significantly reduces its migration from the PLA matrix. 


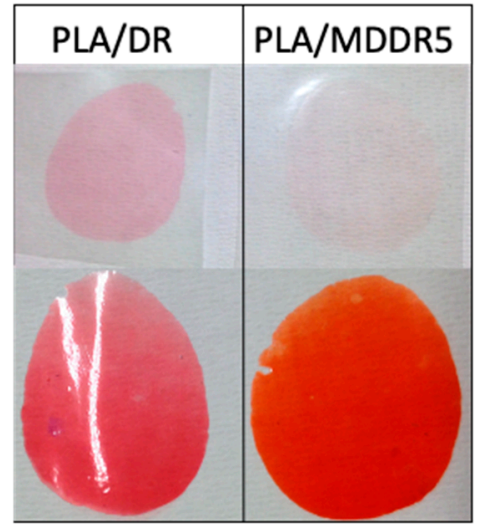

(a)

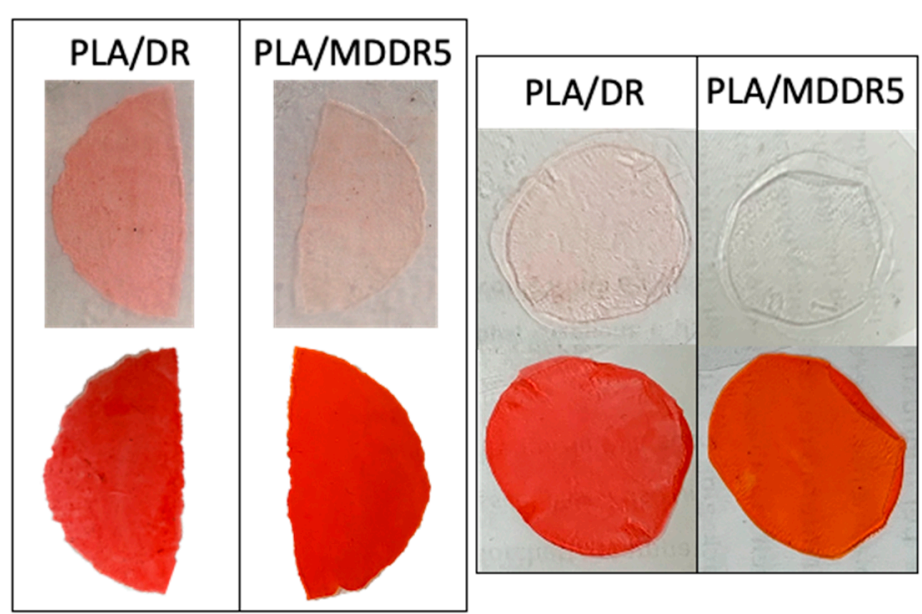

(b)

Figure 10. (a) Pictures of color transfer from PLA/DR or PLA/MDDR5 to poly(ethylene-terephthalate) (PET) at $130{ }^{\circ} \mathrm{C}$. Upper part of the picture: PET films where the spots of DR (left) and MDDR (right) are present. Lower part of the picture: PLA/DR (left) and PLA/MDDR5 (right) film after the contact with PET. (b) Pictures of color transfer from PLA/DR or PLA/MDDR5 to styrene butadiene copolymer (SBC) at $120^{\circ} \mathrm{C}$ on the right and at $100{ }^{\circ} \mathrm{C}$ on the left. Upper part of the pictures: styrene butadiene copolymer (SBC) films where the spots of DR and MDDR are present. Lower part of the pictures: PLA/DR and PLA/MDDR5 film after contact with SBC (see the text and Section 2.5 for details.).

Other migration tests are carried out starting from solid PLA samples taking advantage of the fact that an asymmetric phase distribution of a polymeric blend can be obtained by its compression molding between two surfaces having different polarity like Teflon and aluminum sheet [44]. Generally speaking, enrichment on the surface of one constituent of a polymer blend has important implications in those applications that involve the surface properties like wettability, adhesive interactions, and fouling resistance [45]. Taking inspiration from these observations, films of PLA/CA and PLA/MDCA5 are hot melted at $180{ }^{\circ} \mathrm{C}$ between aluminum and Teflon sheets. The surface energy of aluminum is $39.5 \mathrm{~mJ} / \mathrm{m}^{2}$, that of Teflon is $13.6 \mathrm{~mJ} / \mathrm{m}^{2}$ [44], and that of PLA is $42 \mathrm{~mJ} / \mathrm{m}^{2}$ [45]. CA has a polar group, and for this reason, it is expected that its migration is favored towards aluminum rather than towards Teflon that has a lower surface energy. After compression molding between aluminum and Teflon and quenching at low temperature, the two faces of PLA films were analyzed by fluorescence emission. In the case of PLA/CA, the spectrum collected from the aluminum-exposed side was more intense than that recorded from the Teflon side (Figure 11, full symbols); in the case of PLA/MDCA, the spectra recorded from both faces had the same intensity (Figure 12, full symbols). As hypothesized, CA migrates and accumulates on the surface facing to aluminum, but migration occurred only in PLA/CA; indeed, when MDCA was mixed to PLA, no surface segregation of chromophore was observed. The samples just described were annealed at $110{ }^{\circ} \mathrm{C}$ for $18 \mathrm{~h}$ by maintaining the contact of the film surfaces with aluminum or Teflon. This procedure was performed with the aim to increase the crystallinity of PLA because it is expected that chromophores are dispersed into the amorphous phase of the matrix and an increase of crystallinity can induce chromophores to aggregate or to further accumulate on the surface. The emission spectra collected after annealing (Figures 11 and 12 empty symbols) showed that, in the case of PLA/CA, the fluorescence intensity increased and it was similar on both sides of the film: no excimer emission was detected. The fact that fluorescence intensity was similar on both sides suggested that the increase of crystallinity caused the accumulation of chromophore on both sides independently from the different polarity of the surfaces in contact with PLA. In the case of PLA/MDCA, the fluorescence intensity was slightly lower after annealing than before; probably in this case, no migration was possible because of the presence of the PLA chain bonded to the chromophore that can be involved in the formation of crystals within the PLA chains constituting the matrix. Finally, it can be observed that the relative 
intensity of the band at about 350 and $360 \mathrm{~nm}$ was changed by the annealing process (Table S6, Supplementary Materials). As previously discussed, the lower intensity of the band at about 350 $\mathrm{nm}$ with respect to the band at about $360 \mathrm{~nm}$ can be associated with the presence of aggregates. Interestingly, in PLA/CA and PLA/MDCA5 after annealing, the ratio between the band intensity at 350 and $360 \mathrm{~nm}$ was lower than before annealing (see Figure 11 and Table S6, Supplementary Materials), and this occurred on both sides. This suggests that, after annealing, the segregation of chromophores induced by the increase of crystallinity of PLA, caused also the formation of aggregates even if in the case of PLA/MDCA5 (see Table S6, Supplementary Materials) the effect was less evident.

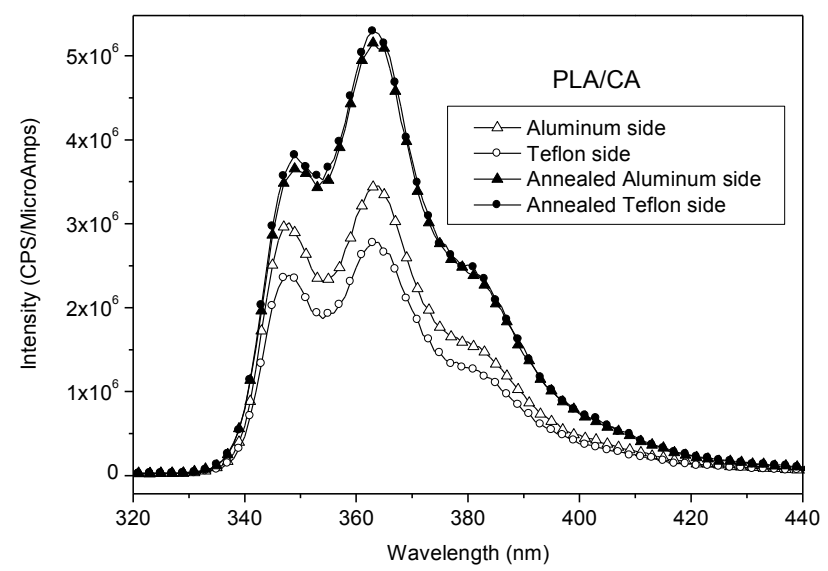

Figure 11. Fluorescence emission spectra collected from PLA/CA before and after annealing from the aluminum and Teflon sides.

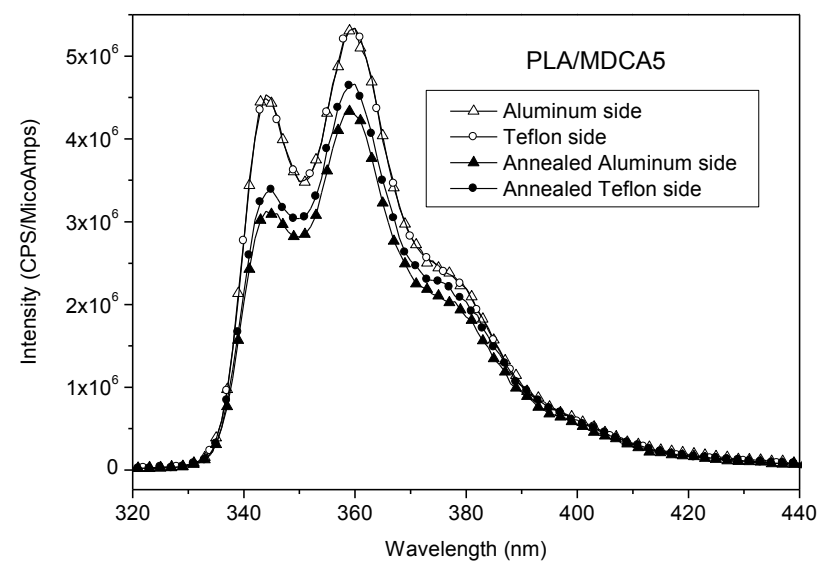

Figure 12. Fluorescence emission spectra collected from PLA/MDCA5 before and after annealing from the aluminum and Teflon sides.

The results achieved in this paper could be interesting also in the field of fabrics or textile where fibers of PLA are used. This could be particularly important because PLA fibers are emerging as an eco-friendly alternative to conventional PET fibers. The affinity between the fiber and the dye is one of the key parameters that control dying of the PLA fibers. Disperse dyes are indeed "absorbed" or better exhausted by the fibers, and the process could be considered the dissolution of disperse dyes in a solid solvent (the polymer fiber) [2,3,39]. This can be facilitated, as proven here, if the chromophores contain a long PLA chain. Moreover, the "thermo migration" and the "storage migration" [46,47] of dyes can also be in part limited by using dyes having high molecular weight or high affinity for the fibers. These undesired processes occur during the production of dyed and during their storage. By this phenomenon, the dye accumulates on the surface of the fiber and can be lost by sublimation, can be removed during subsequent washing, or can stain adjacent fabrics, causing an overall depletion of the appearance of the fibers. 


\subsection{Microwave Assisted Polymerization of L-lactide in the Presence of FM as Co-initiator}

In the case of FM in parallel to the classical ROP reaction carried out, heating the reaction mixture at $130{ }^{\circ} \mathrm{C}$, a series of microwave-assisted polymerization reactions were performed. Microwaves were considered an efficient energy source for the synthesis of polymers, with an impressive potential in terms of time and energy economy and sometimes capable of inducing specific nonthermal effects [48-51]. By this way, microwave-assisted polymerization of L-lactide can proceed faster, with high purity and consequently with high yield if compared with the classical lactide polymerization. Finally, lactide, lactic acid, and its oligomer are polar molecules so they can absorb microwave energy, thus increasing the temperature of the reaction [19]. In the literature, there are few examples that use a co-initiator in the preparation of PLA by microwave irradiation [52-54], and to the best of our knowledge, FM that is a chromophore, is for the first time used as a co-initiator in the ROP of L-lactide under microwave irradiation. Experimental details for the preparation of macromolecular dyes end capped with FM prepared by microwave-assisted polymerization of L-lactide (MDFMmws) are reported in the Supplementary Materials. The conversion of L-lactide, PD, Mn evaluated by ${ }^{1} \mathrm{H}-\mathrm{NMR}$, Mn and $Đ$ evaluated by SEC analysis, and Mn calculated on the basis of L-lactide/initiator in the feed are reported in Table 4.

Table 4. Conversion of L-lactide to MDs, PD, Mn determined by ${ }^{1} \mathrm{H}-\mathrm{NMR}$ and by SEC, Mn calculated on the basis of L-lactide/initiator in the feed, and Đ determined by SEC. ${ }^{1}$.

\begin{tabular}{|c|c|c|c|c|c|c|}
\hline Entry & $\begin{array}{c}\text { Conversion } \\
(\%)^{2}\end{array}$ & $\begin{array}{c}\text { PD } \\
(\mathrm{NMR})^{3}\end{array}$ & $\begin{array}{c}\text { Mn (NMR) } \\
(\mathrm{g} / \mathrm{mol})^{4}\end{array}$ & $\begin{array}{l}\text { Mn (SEC) } \\
(\mathrm{g} / \mathrm{mol})^{5}\end{array}$ & $\begin{array}{c}\mathrm{Mn}(\mathrm{CAL}) \\
(\mathrm{g} / \mathrm{mol})^{6}\end{array}$ & $Đ(\mathrm{SEC})^{7}$ \\
\hline MDFMmw1 & 93 & 52 & 3940 & 3321 & 13,457 & 1.7 \\
\hline MDFMmw3 & 90 & 38 & 2932 & 4389 & 4568 & 1.5 \\
\hline MDFMmw5 & 88 & 29 & 2284 & 2981 & 3050 & 1.4 \\
\hline MDFMmw7 & 77 & 27 & 2140 & 2006 & 2234 & 1.2 \\
\hline MDFMmw10 & 79 & 16 & 1348 & 2105 & 1623 & 1.2 \\
\hline MDFM1 & 92 & 9 & 845 & 2262 & 13,457 & 1.2 \\
\hline MDFM3 & 91 & 10 & 917 & 2146 & 4568 & 1.1 \\
\hline MDFM5 & 99 & 26 & 2142 & 3822 & 3050 & 1.2 \\
\hline MDFM7 & 99 & 19 & 1566 & 1682 & 2234 & 1.1 \\
\hline MDFM10 & 99 & 4 & 485 & 1334 & 1623 & 1.1 \\
\hline
\end{tabular}

${ }^{1}$ MDFMs data are reported for comparison. ${ }^{2}$ Conversion of lactide $\left(\left(\mathrm{LA}_{0}-\mathrm{LA}\right) / \mathrm{LA}_{0}\right) \times 100$, where $\mathrm{LA}_{0}$ is the amount of lactide in the feed and LA is the amount of unreacted lactide at the end of reaction. The amount of unreacted lactide is quantitatively evaluated by ${ }^{1} \mathrm{H}-\mathrm{NMR}$ by signal integration of the quartet associated with the $\mathrm{C}$ of residual L-lactide (5.04 ppm) and that of the repetitive unit of MDs (5.16 ppm). ${ }^{3}$ Determined by calculating the ratio between integrals of $\underline{\mathrm{CH}}$ quartet in the repetitive unit $(5.16 \mathrm{ppm})$ and terminal $\mathrm{C} \underline{\mathrm{H}}$ quartet $(4.36 \mathrm{ppm}) \mathrm{of}$ MDs; values are approximated to the nearest whole number. ${ }^{4} \mathrm{Mn}$ determined by ${ }^{1} \mathrm{H}-\mathrm{NMR}$ analysis $(\mathrm{PD} \times 72$ (lactic acid molecular weight) $+\mathrm{M}_{\mathrm{i}}$ ), where $\mathrm{M}_{\mathrm{i}}$ is the molecular weight of initiator. ${ }^{5} \mathrm{Mn}$ determined by SEC analysis and corrected by multiplying 0.58 [12]. ${ }^{6}$ Theoretically calculated $\mathrm{Mn}=144.137$ (molecular weight of lactide) $\times$ $\mathrm{LA}_{0} / \mathrm{I}_{0} \times$ conversion $+\mathrm{M}_{\mathrm{i}}$, where $\mathrm{I}_{0}$ is the mole of initiator in the feed. ${ }^{7} Ð$ determined by SEC.

From the data reported in Table 4, it can be observed that the microwave-assisted polymerization of L-lactide initiated by FM generally gives a higher degree of polymerization and consequently higher molecular weight than the classical thermal polymerization of L-lactide. However, for the samples prepared using a higher co-initiator/L-lactide ratio, a lower conversion of the monomer with respect to the classical ROP is observed. Notably, these data are obtained by using a quite shorter reaction time than that used in the conventional thermal reaction; thus, microwave-assisted polymerization can be considered an energy-saving process with respect to other polymerization procedures.

The molecular weight of the sample is determined by SEC analysis. Chromatographic curves (Figure 13) evidence a main peak eluting between 17 and $20 \mathrm{~min}$ due to MDFMmws and some other peaks eluting at a longer retention time. As previously discussed, these peaks can be associated with the presence of an unreacted monomer, the co-initiator, or oligomers. Comparison between the chromatographic curves of MDFMmws with those of MDFMs prepared by the classical thermal 
polymerization (Figure 13) shows that the molecular weight of MDFMmws is generally higher than that of MDFMs. However, in some samples, especially those prepared by using a low concentration of FM with respect to L-lactide (MDFMmw1 and 3), the main elution peak is bimodal. From the corresponding profile, it can be hypothesized that two families of macromolecules are present in the samples MDFMmw1 and MDFMmw3; however, their formation and their nature are not certain. Although it is difficult to hypothesize the origin of these two populations, the literature suggests that transesterification reactions can occur during polymerization [48]. Transesterification may occur by inter- and intramolecular mechanisms giving, in the first case, an enlargement of molecular weight distribution curves and, in the second case, cyclic polymers. Moreover, for longer reaction times, some authors report also that some degradation phenomena can occur [47]. Alternatively, the two polymer families can be formed independently because of the occurrence of two polymerization processes initiated by different co-initiators, such as FM and water.

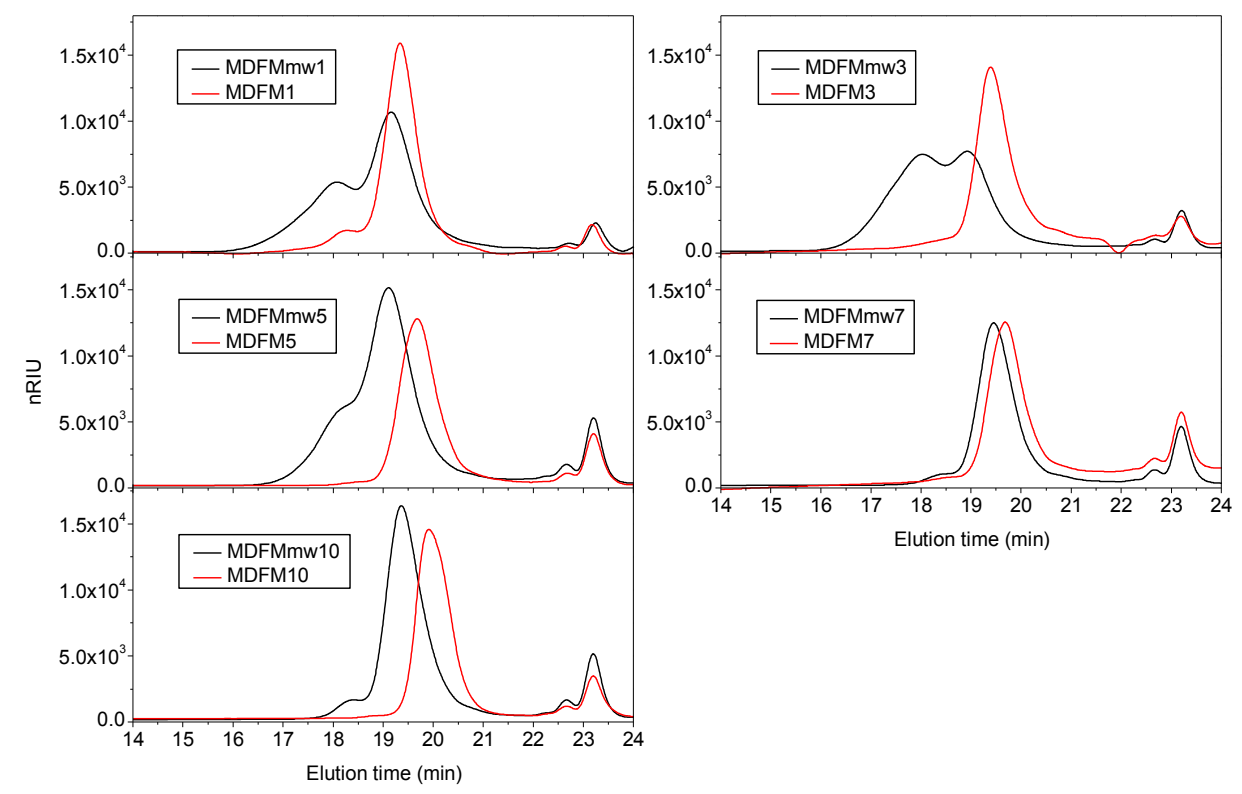

Figure 13. Comparison between chromatograms collected during SEC analysis of the macromolecular dyes samples prepared by microwave-assisted polymerization of L-lactide and by using 1-10 mol\% of FM (MDFMmw1-MDFMmw10) and MDFM1-MDFM10.

MDFMmws were also analyzed by DSC (Figure 14; Table S7, Supplementary Materials). The samples showed thermal properties that are similar to those collected for the other MDs. As in the MDFMs samples, also in this case, melting temperatures shifted to higher temperatures with the increase of molecular weight. Two crystalline forms were generally present, both in the first and second heating scans. During the second heating scan, all samples showed a cold crystallization process; the only exception was MDFMmw10. Finally, the enthalpies associated with this process and the melting one were similar, suggesting that the fraction of the sample that crystallizes at $T_{\mathrm{cc}}$ melted at $T_{\mathrm{m}}$. 


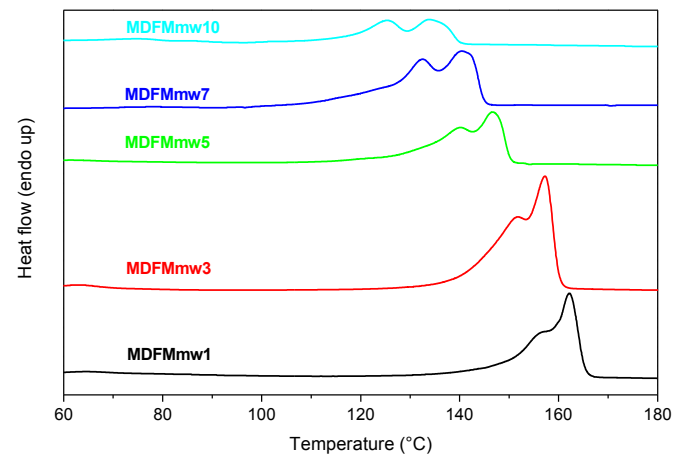

(a)

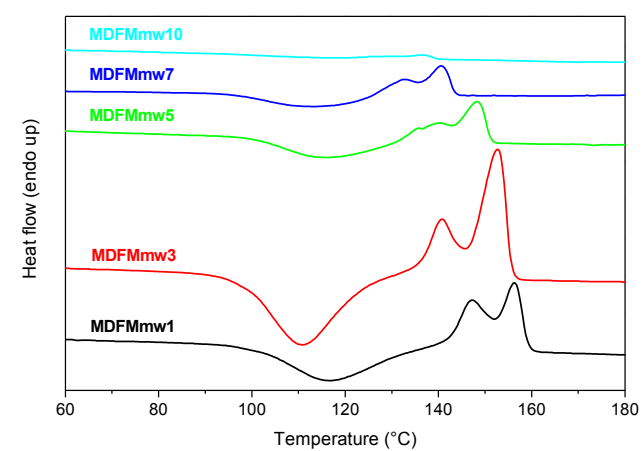

(b)

Figure 14. DSC curves of first heating (a) and second heating (b) scans of samples MDFMmw1-MDFMmw10: Heating and cooling scans were carried out at $20^{\circ} \mathrm{C} / \mathrm{min}$. The curves are vertically shifted for clarity.

\section{Conclusions}

MDs have been prepared by chromophore-initiated ring opening polymerization of L-lactide catalyzed by $\mathrm{Sn}(\mathrm{Oct})_{2}$. Three different chromophores (i.e., CA, FM, and DR) were tested, and variable co-initiator/L-lactide ratios were investigated to tune the molecular weight of MDs. This study reports also for the first time the microwave-assisted polymerization of L-lactide with a chromophore (FM) as a successful example of energy-saving process.

Generally, higher conversion and better control of molecular weight distribution were obtained by using CA and FM in a low concentration with respect to L-lactide. Interestingly, MDs showed thermal properties dependent on molecular weight and photophysical characteristics that are similar to those of free chromophores used as co-initiators. This last feature suggests that it may be possible to use the optical response of MDs in different applications.

Thanks to the presence of PLA chains bonded to chromophores, the affinity of MDs for PLA is increased and the volatility of chromophores is reduced. Therefore, a dyed PLA (PLA/MD) was successfully obtained by blending MDs with PLA. Interestingly, the photophysical properties of PLA/MDs are very similar to those of free chromophores and of MDs. Moreover, they are characterized by thermal properties similar to that of the PLA matrix, confirming that these materials are suitable for packaging applications.

Migration tests carried out by using different methods definitely confirmed that MDs are significantly less released from PLA films than free chromophores. This was strong evidence that the immobilization of chromophores in MDs significantly reduces their migration from the PLA matrix. Moreover, in the case of PLA/MDCA, a variation of the vibrational structure of the emission spectrum was observed after annealing. In this case, the material has the ability to respond to external stimuli and it can be considered thermo-responsible. The optical response, indeed, may be changed simply by heating the material, and in this way, it could be possible to visualize if it has been subject to unwanted heating processes.

Another interesting remark emerging from the data discussed in the paper deals with the photophysical properties of MDCA and MDFM. Indeed, these two MDs absorb UV-A and UV-B but are transparent to visible light. This makes the films transparent and the dye invisible to the naked eye, suggesting their use in the production of films for food packaging because they can protect food from dangerous UV radiation and are transparent. In addition, these materials may be used for the production of UV-protecting garments. Furthermore, it may be possible to use the fluorescent response of MDCA and MDFM in anti-counterfeit applications.

Finally, all data so far discussed concern PLA films; however, the results achieved in this paper could be interesting also in the field of fabrics or textiles where fibers of PLA are used because our macromolecular dyes can effectively limit the problem of "storage migration". 
Supplementary Materials: The following are available online at http://www.mdpi.com/2073-4360/12/9/1979/s1, Figure S1. ${ }^{1} \mathrm{H}-\mathrm{NMR}$ of a crude polymerization product and enlargement on the $\mathrm{CH}$ quartet signals of L-lactide centered at $5.04 \mathrm{ppm}$ and of MD main chain centered at $5.16 \mathrm{ppm}$, monitored to assess lactide conversion; Figure S2. FT-IR spectra of L-lactide (top) and polylactide (bottom); Figure S3. ${ }^{1} \mathrm{H}-\mathrm{NMR}$ spectrum of MDFM5 $\left(\mathrm{CDCl}_{3}\right)$; Figure S4. ${ }^{1} \mathrm{H}-\mathrm{NMR}$ spectrum of MDDR5 $\left(\mathrm{CDCl}_{3}\right)$; Figure S5. Chromatograms collected during SEC analysis of samples a) MDFM1-MDFM10 and b) MDDR1-MDDR7; Figure S6. DSC curves of the first heating (a) and second heating (b) scans of samples MDFM1-MDFM10: heating and cooling scans were carried out at $20{ }^{\circ} \mathrm{C} / \mathrm{min}$. The curves are vertically shifted for clarity; Figure S7. DSC curves of the first heating (a) and second heating (b) scans of samples MDDR1-MDDR7: heating and cooling scans were carried out at $20^{\circ} \mathrm{C} / \mathrm{min}$. The curves are vertically shifted for clarity; Figure S8. DSC curves of the second heating scan of samples MDCA5, MDFM5, and MDDR5: heating and cooling scans were carried out at $10^{\circ} \mathrm{C} / \mathrm{min}$. The curves are vertically shifted for clarity; Figure S9. Chromatograms collected during SEC analysis of PLA/MDCA5, PLA/MDFM5, and PLA/MDDR5; Figure S10. DSC curves (second heating scan) of PLA, PLA/MDCA5, PLA/MDFM5, and PLA/MDDR5 (a) and of PLA, PLA/CA, PLA/FM, and PLA/DR (b): the curves are vertically shifted for clarity. Heating and cooling scans were carried out at $10{ }^{\circ} \mathrm{C} / \mathrm{min}$. Table S1. Absorption maxima of MDCA5, MDFM5, and MDDR5 in $\mathrm{CHCl}_{3}$ and calculated amount of chromophore in MDs in comparison with the theoretical value in the feed; Table S2. Main FT-IR band of L-lactide and PLA; Table S3. DSC data of MDs; Table S4. DSC data of MDs prepared by using $5 \mathrm{~mol} \%$ of an initiator: second heating scan; Table S5. Absorption maxima and corresponding molar extinction coefficients of $\mathrm{CA}, \mathrm{FM}$, and DR in $\mathrm{CHCl}_{3}$ and in $\mathrm{EtOH} \mathrm{95 \% ;} \mathrm{Table} \mathrm{S6.} \mathrm{The} \mathrm{ratio} \mathrm{between} \mathrm{the} \mathrm{emission} \mathrm{intensity}$ of the band at 350 and $360 \mathrm{~nm}$ of the spectra of PLA/CA and PLA/MDCA5; Table S7. DSC data of MDFMmws. Scheme S1. (1) Propagation reaction: the active chain attacks the ester bond of lactone, where the opposite reaction is the depolymerization, and (2) intermolecular transfer reaction: the active chain attacks an ester bond internal to another polymer chain, where this chain can be active (metal alkoxide terminated) or dormant (alcohol terminated): Microwave-assisted synthesis of Macromolecular Dyes (MD) by using FM as a co-initiator.

Author Contributions: Conceptualization, F.C., L.R., S.C., E.P., and M.F.; methodology, F.C. and M.F.; investigation, F.C., G.G., R.S., and F.P.; resources, E.P. and M.F.; writing-original draft preparation, F.C.; writing-review and editing, F.C., G.G., L.R., E.P., S.C., R.S., F.P., and M.F.; visualization, F.C.; supervision, F.C., L.R., and M.F.; project administration, F.C. and M.F.; funding acquisition, E.P. and M.F. All authors have read and agreed to the published version of the manuscript.

Funding: This research is partially funded by the National Project "New Polymer Systems with Electric and Optical Functionalities via Nano and Micro Adhesive Dispersion to Produce Materials and Devices for Smart Applications" POLOPTEL 2011-2014, La Fondazione CARIPISA conv. 167/09 and by MIUR (PRIN 2008), “Materiali nanoibridi a base biopoliesteri: miscelazione reattiva di sistemi organici e inorganici opportunamente modificati", contract grant number: 200898KCKY.

Acknowledgments: Anna Maria Papini is acknowledged for her assistance during microwave polymerization. We thank MIUR-Italy ("Progetto Dipartimenti di Eccellenza 2018-2022" allocated to Department of Chemistry "Ugo Schiff").

Conflicts of Interest: The authors declare no conflict of interest. The funders had no role in the design of the study; in the collection, analyses, or interpretation of data; in the writing of the manuscript; or in the decision to publish the results.

\section{References}

1. Farah, S.; Anderson, D.G.; Langer, R. Physical and mechanical properties of PLA, and their functions in widespread applications-A comprehensive review. Adv. Drug Deliv. Rev. 2016, 107, 367-392. [CrossRef] [PubMed]

2. Cui, Z.; Wang, X.; Chen, W.; Hua, E.; Liu, K. Synthesis, spectral and dyeing properties of phenylazopyrazolone-containing acylamide disperse dyes designed for poly(lactic acid). Color. Technol. 2012, 128, 283-289. [CrossRef]

3. Hussain, T.; Tausif, M.; Ashraf, M. A review of progress in the dyeing of eco-friendly aliphatic polyester based polylactic acid fabrics. J. Clean. Prod. 2015, 108, 476-483. [CrossRef]

4. Ge, F.; Ding, Y.; Yang, L.; Huang, Y.; Jiang, L.; Dan, Y. Effect of the content and distribution of ultraviolet absorbing groups on the UV protection and degradation of polylactide films. RSC Adv. 2015, 5, 70473-70481. [CrossRef]

5. Hu, Y.; Daoud, W.A.; Cheuk, K.K.L.; Lin, C.S.K. Newly developed techniques on polycondensation, ring-opening polymerization and polymer modification: Focus on poly(lactic acid). Materials 2016, 9, 133-147. [CrossRef]

6. Dechy-Cabaret, O; Martin-Vaca, B.; Bourissou, D. Controlled ring-opening polymerization of lactide and glycolide. Chem. Rev. 2004, 104, 6147-6176. [CrossRef] 
7. Gupta, A.P.; Kumar, V. New Emerging Trends in synthetic biodegradable polymers-Polylactide: A critique. Eur. Polym. J. 2007, 43, 4053-4074. [CrossRef]

8. Williams, C.K. Synthesis of functionalized biodegradable polyesters. Chem. Soc. Rev. 2007, 36, 1573-1580. [CrossRef]

9. Nguyen, C.A.; Allémann, E.; Schwach, G.; Doelker, E.; Gurny, R. Synthesis of a novel fluorescent poly(D,L-Lactide) end-capped with 1-pyrenebutanol used for the preparation of nanoparticles. Eur. J. Pharm. Sci. 2003, 20, 217-222. [CrossRef]

10. Alwattar, A.; Haddad, A.; Zhou, Q.; Nascimento, T.; Greenhalgh, R.; Medeiros, E.; Blaker, J.; Parry, A.; Quaylea, P.; Yeatesa, S. Synthesis and characterisation of fluorescent pyrene-end-capped polylactide fibres. Polym. Int. 2019, 68, 360-368. [CrossRef]

11. Yildirim, I.; Bus, T.; Sahn, M.; Yildirim, T.; Kalden, D.; Hoeppener, S.; Traeger, A.; Westerhausen, M.; Weber, C.; Schubert, U.S. Fluorescent amphiphilic heterografted comb polymers comprising Biocompatible PLA and PEtOx side chains. Polym. Chem. 2016, 7, 6064-6074. [CrossRef]

12. Ge, F.; Huang, Y.; Luo, Y.; Jiang, L.; Dan, Y. Macromolecular chain structure design, synthesis and analysis of poly(L-lactide) linking ultraviolet absorbing groups. RSC Adv. 2014, 4, 63118-63127. [CrossRef]

13. Ten Breteler, M.R.; Feijen, J.; Dijkstra, P.J.; Signori, F. Synthesis and thermal properties of hetero-bifunctional PLA oligomers and their stereocomplexes. React. Funct. Polym. 2013, 73, 30-38. [CrossRef]

14. Burgos, N.; Tolaguera, D.; Fiori, S.; Jiménez, A. Synthesis and characterization of lactic acid oligomers: Evaluation of performance as poly(lactic acid) plasticizers. J. Polym. Environ. 2014, 22, 227-235. [CrossRef]

15. Báez, J.E.; Marcos-Fernández, Á.; Galindo-Iranzo, P. Exploring the effect of alkyl end group on poly(L-lactide) oligo-esters. Synthesis and characterization. J. Polym. Res. 2011, 18, 1137-1146. [CrossRef]

16. Giuntoli, G.; Rosi, L.; Frediani, M.; Sacchi, B.; Frediani, P. Fluoro-functionalized PLA polymers as potential water-repellent coating materials for protection of stone. J. Appl. Polym. Sci. 2012, 125, 3125-3133. [CrossRef]

17. Fischer, E.W.; Sterzel, H.J.; Wegner, G. Investigation of the structure of solution grown crystals of lactide copolymers by means of chemical reactions. Kolloid Z. Z. Polym. 1973, 251, 980-990. [CrossRef]

18. Inkinen, S.; Hakkaramen, M.; Albertsson, A.-C.; Södergård, A. From lactic acid to poly(lactic acid) (PLA): Characterization and analysis of PLA and its precursors. Biomacromolecules 2011, 12, 523-532. [CrossRef]

19. Nikolic, L.; Ristic, I.; Adnadjevic, B.; Nikolic, V.; Jovanovic, J.; Stankovic, M. Novel microwave-assisted synthesis of poly(D,L-lactide): The influence of monomer/initiator molar ratio on the product properties. Sensors 2010, 10, 5063-5073. [CrossRef]

20. Witzke, D.R.; Narayan, R. Reversible kinetics and thermodynamics of the homopolymerization of L-lactide with 2-ethylhexanoic acid tin(II) salt. Macromolecules 1997, 30, 7075-7085. [CrossRef]

21. De Jong, S.J.; van Dijk-Wolthuis, W.N.E.; Kettenes-van den Bosch, J.J.; Schuyl, P.J.W.; Hennink, W.E. Monodisperse enantiomeric lactic acid oligomers: Preparation, characterization, and stereocomplex formation. Macromolecules 1998, 31, 6397-6402. [CrossRef]

22. Ubeda, S.; Aznar, M.; Alfaro, P.; Nerín, C. Migration of oligomers from a food contact biopolymer based on polylactic acid (PLA) and polyester. Anal. Bioanal. Chem. 2019, 411, 3521-3532. [CrossRef] [PubMed]

23. Penczek, S.; Duda, A.; Szymanski, R. Intra- and intermolecular chain transfer to macromolecules with chain scission, the case of cyclic esters. Macromol. Symp. 1998, 132, 441-449. [CrossRef]

24. Yu, Y.; Storti, G.; Morbidelli, M. Ring-opening polymerization of L,L-lactide: Kinetic and modeling study. Macromolecules 2009, 42, 8187. [CrossRef]

25. Kowalski, A.; Libiszowski, J.; Duda, A.; Penczek, S. Kinetics and mechanism of cyclic esters polymerization initiated with tin(II) octoate. 3 polymerization of L,L-dilactide. Macromolecules 2000, 33, 7359-7370. [CrossRef]

26. Saeidlou, S.; Huneault, M.A.; Li, H.; Park, C.B. Poly(lactic acid) crystallization. Prog. Polym. Sci. 2012, 37, 1657-1677. [CrossRef]

27. Rathi, S.; Kalish, J.P.; Coughlin, E.B.; Hsu, S.L. Utilization of oligo(lactic acid) for studies of chain conformation and chain packing in poly(lactic acid). Macromolecules 2011, 44, 3410-3415. [CrossRef]

28. Pholharn, D.; Srithep, Y.; Morris, J. Effect of initiators on synthesis of poly(L-lactide) by ring opening polymerization. IOP Conf. Ser. Mater. Sci. Eng. 2017, 213, 012022. [CrossRef]

29. Jin, X.; Chen, X.; Cheng, Q.; Zhang, N.; Caia, S.; Ren, J. Non-isothermal crystallization kinetics of ramie fiber-reinforced polylactic acid biocomposite. RSC Adv. 2017, 7, 46014-46021. [CrossRef] 
30. Lakowicz, J.R.; Hogen, D. Chlorinated hydrocarbon-cell membrane interactions studied by the fluorescence quenching of carbazole-labeled phospholipids: Probe synthesis and characterization of the quenching methodology. Chem. Phys. Lipids 1980, 26, 1-40. [CrossRef]

31. Bonesi, S.M.; Erra-Balsells, R. Electronic spectroscopy of carbazole and N- and C-substituted carbazoles in homogeneous media and in solid matrix. J. Lumin. 2001, 93, 51-74. [CrossRef]

32. Nkansah, M.A.; Christy, A.A.; Barth, T.; Francis, G.W. Preliminary photochemical studies of fluorene in various aqueous media. Am. J. Sci. Ind. Res. 2014, 5, 97-103. [CrossRef]

33. Winnik, F.M. Association of hydrophobic polymers in water: Fluorescence studies with labeled (hydroxypropy1)cellulose. Macromolecules 1989, 22, 734-742. [CrossRef]

34. Feng, G.; Qian, H.-F.; Bai, G.; Liu, Y.-C.; Hu, L.-L. Synthesis, characterization, and application of diester/diurethane tethered azo disperse dyes: A new strategy to improve dye's fastness properties. Dyes Pigments 2016, 129, 54-59. [CrossRef]

35. Martins, T.D.; Weiss, R.G.; Atvars, T.D.Z. Synthesis and photophysical properties of a poly(methyl methacrylate) polymer with carbazolyl side groups. J. Braz. Chem. Soc. 2008, 19, 1450-1461. [CrossRef]

36. Zhang, L.; Zhou, J.; Zhang, L. Synthesis and fluorescent properties of carbazole-substituted hydroxyethylcelluloses. Macromol. Chem. Phys. 2012, 213, 57-63. [CrossRef]

37. Heldt, J.; Heldt, J.R.; Redzimski, T.; Diehl, H.; Schultz, P. Spectroscopic studies of dimethylamino derivatives of fluorene. Z. Naturforsch. 2000, 55, 902-908. [CrossRef]

38. Redzimski, T.; Heldt, J.R. Spectroscopic study of solvatochromic effects in solution of amino and hydroxy derivatives of fluorene. J. Fluoresc. 2003, 13, 393-401. [CrossRef]

39. He, L.; Zhang, S.F.; Tang, B.T.; Wang, L.L.; Yang, J.Z. Dyes with high affinity for polylactide. Chin. Chem. Lett. 2007, 18, 1151-1153. [CrossRef]

40. Ojanen, J.; Rantala, T.T. Electronic structure and absorption spectrum of disperse red 1: Comparison of computational approaches. Open Chem. Phys. J. 2009, 2, 37-46. [CrossRef]

41. Airinei, A.; Homocianu, M.; Dorohoi, D.O. Changes induced by solvent polarity in electronic absorption spectra of some azo disperse dyes. J. Mol. Liq. 2010, 157, 13-17. [CrossRef]

42. Priimagi, B.; Cattaneo, S.; Ras, R.H.A.; Valkama, S.; Ikkala, O.; Kauranen, M. Polymer-dye complexes: A facile method for high doping level and aggregation control of dye molecules. Chem. Mater. 2005, 17, 5798-5802. [CrossRef]

43. Pérez Amaro, L.; Cicogna, F.; Passaglia, E.; Morici, E.; Oberhauser, W.; Al-Malaika, S.; Dintcheva, N.T.; Coiai, S. Thermo-oxidative stabilization of poly(lactic acid) with antioxidant intercalated layered double hydroxides. Polym. Degrad. Stab. 2016, 113, 92-100. [CrossRef]

44. Bertoldo, M.; Coltelli, M.B.; Miraglia, L.; Narducci, P.; Bronco, S. Surface energy inducing asymmetric phase distribution in films of a binary polymeric blend. Polymer 2005, 46, 11311-11321. [CrossRef]

45. Stein, G.E.; Laws, T.S.; Verduzco, R. Tailoring the attraction of polymers toward surfaces. Macromolecules 2019, 52, 4787-4802. [CrossRef]

46. Avinc, O.; Phillips, D.; Wilding, M. Influence of different finishing conditions on the wet fastness of selected disperse dyes on polylactic acid fabrics. Color. Technol. 2009, 125, 288-295. [CrossRef]

47. Avinc, O.; Wilding, M.; Bone, J.; Phillips, D.; Farrington, D. Evaluation of color fastness and thermal migration in softened polylactic acid fabrics dyed with disperse dyes of differing hydrophobicity. Color. Technol. 2010, 126, 353-364. [CrossRef]

48. Frediani, M.; Giachi, G.; Rosi, L.; Frediani, P. Synthesis and Processing of Biodegradable and Bio-Based Polymers by Microwave Irradiation; Usha, C., Ed.; InTech: London, UK, 2010; ISBN 978-953-307-573-0. Available online: http://www.intechopen.com/books/microwaveheating/synthesis-and-processing-of-biodegradableand-bio-based-polymers-by-microwave-irradiation (accessed on 6 July 2019).

49. Frediani, M.; Sémeril, D.; Matt, D.; Rosi, L.; Frediani, P.; Rizzolo, F.; Papini, A.M. Ring-opening polymerisation of rac -lactide using a calix[4]arene-based titanium (IV) complex. Int. J. Polym. Sci. 2010. [CrossRef]

50. Hoogenboom, R.; Schubert, U.S. Microwave-assisted polymer synthesis: Recent developments in a rapidly expanding field of research. Macromol. Rapid Commun. 2007, 28, 368-386. [CrossRef]

51. Sosnik, A.; Gotelli, G.; Abraham, G.A. Microwave-assisted polymer synthesis (MAPS) as a tool in biomaterials science: How new and how powerful. Prog. Polym. Sci. 2011, 36, 1050-1078. [CrossRef] 
52. Dubey, S.P.; Abhyankar, H.A.; Marchante, V.; Brighton, J.L.; Bergmann, B.; Trinhc, G.; David, C. Microwave energy assisted synthesis of poly lactic acid via continuous reactive extrusion: Modelling of reaction kinetics. RSC Adv. 2017, 7, 18529-18538. [CrossRef]

53. Li, G.; Zhao, N.; Bai, W.; Chen, D.L.; Xiong, C.D. Microwave-assisted ring- opening polymerization of poly(glycolic acid-co-lactic acid) copolymers. e-Polymers 2010, 51, 1-6. [CrossRef]

54. Zhang, C.; Liao, L.; Gong, S. Microwave-assisted synthesis of PLLA-PEG-PLLA triblock copolymers. Macromol. Rapid Commun. 2007, 28, 422-427. [CrossRef]

(C) 2020 by the authors. Licensee MDPI, Basel, Switzerland. This article is an open access article distributed under the terms and conditions of the Creative Commons Attribution (CC BY) license (http://creativecommons.org/licenses/by/4.0/). 